NBER WORKING PAPER SERIES

\author{
TECHNOLOGY, EMPLOYMENT, AND \\ THE BUSINESS CYCLE: DO TECHNOLOGY \\ SHOCKS EXPLAIN AGGREGATE \\ FLUCTUATIONS?
}

\author{
Jordi Galí \\ Working Paper 5721
NATIONAL BUREAU OF ECONOMIC RESEARCH
1050 Massachusetts Avenue
Cambridge, MA 02138
August 1996

\begin{abstract}
I am grateful to Susanto Basu, Bill Brainard, Martin Eichenbaum, Mark Gertler, Lutz Killian, Franck Portier, Xavier Sala-i-Martin, Julio Rotemberg, Chris Sims, and workshop participants at the New York Fed, NYU, Yale University, and the NBER 1996 Summer Institute for helpful comments and suggestions. Tommaso Monacelli provided excellent research assistance. I thank Universitat Pompeu Fabra for its hospitality. Financial support from the C.V. Starr Center for Applied Economics and a DGICYT grant (PB93-0388) are gratefully acknowledged. This paper is part of NBER's research program in Economic Fluctuations and Growth. Any opinions expressed are those of the author and not those of the National Bureau of Economic Research.

(C) 1996 by Jordi Galí. All rights reserved. Short sections of text, not to exceed two paragraphs, may be quoted without explicit permission provided that full credit, including $\mathbb{\odot}$ notice, is given to the source.
\end{abstract}




\title{
TECHNOLOGY, EMPLOYMENT, AND \\ THE BUSINESS CYCLE: DO TECHNOLOGY \\ SHOCKS EXPLAIN AGGREGATE \\ FLUCTUATIONS?
}

\begin{abstract}
Using data for the G7 countries, I estimate conditional correlations of employment and productivity, based on a decomposition of the two series into technology and non-technology components. The picture that emerges is hard to reconcile with the predictions of the standard Real Business Cycle model. For a majority of countries the following results stand out: (a) technology shocks appear to induce a negative comovement between productivity and employment, counterbalanced by a positive comovement generated by demand shocks, (b) the impulse responses show a persistent decline of employment in response to a positive technology shock, and (c) measured productivity increases temporarily in response to a positive demand shock. More generally, the pattern of economic fluctuations attributed to technology shocks seems to be largely unrelated to major postwar cyclical episodes. A simple model with monopolistic competition, sticky prices, and variable effort is shown to be able to account for the empirical findings.
\end{abstract}

Jordi Galí

Department of Economics

New York University

269 Mercer Street

New York, NY 10003

and NBER

galij@fasecon.econ.nyu.edu 


\section{Introduction}

Real Business Cycle (RBC) theory, exemplified by the work of Kydland and Prescott (1982) and its subsequent extensions, interprets the bulk of aggregate fluctuations observed in the postwar US economy as being consistent with the competitive equilibrium of a neoclassical growth model augmented with a labor-leisure choice and exogenous technology shocks. In addition to its theoretical appeal, proponents of the RBC paradigm point to its successful empirical performance as a reason for taking seriously its account of the mechanisms through which shocks impact the economy and are propagated over time.

In the present project I question the usefulness of the type of evidence generally provided in support of RBC models, and which stresses their apparent ability to match the patterns of unconditional second moments of key macroeconomic time series. ${ }^{1}$ The main argument builds upon a well known property of calibrated RBC models driven by technology shocks: a high positive correlation between labor productivity and employment (or hours). The source of that correlation lies at the root of the mechanism underlying macro fluctuations in those models: it reflects the shift in the labor demand schedule caused by technology shocks (and, to a less extent, the induced capital accumulation), combined with an upward sloping (and less variable) labor supply. As is well known, the above prediction stands in stark contrast with the zero or slightly negative correlation detected in the data, an observation which has led a number of researchers to augment the model with non-technology shocks, i.e., with shocks that would act predominantly as labor supply shifters (see, e.g., Christiano and Eichenbaum (1992)). Under that view, the observed near-zero correlation between employment and productivity is the result of the coexistence of technology shocks with other shocks, so that the positive correlation induced by the former is roughly offset

\footnotetext{
${ }^{1}$ See Kydland and Prescott (1996) for a description of the approach to model evaluation found in much of the RBC literature, and Sims $(1989,1996)$ for a critical appraisal of that approach. Examples of attempts to evaluate RBC models by focusing on other dimensions of their predictions include Watson (1993), Gali (1994), and Rotemberg and Woodford (1996).
} 
by the negative correlation resulting from the latter. ${ }^{2}$

In section 2 of the present paper I show how a stylized model with monopolistic competition, sticky prices and variable effort can potentially explain the near-zero unconditional correlation between productivity and employment while reversing its sources: under plausible assumptions, the model predicts that technology shocks generate a negative comovement between those two variables, offset by the positive comovement arising from demand shocks. The intuition for the results is straightforward. In equilibrium, aggregate demand (and, consequently, the demand faced by each individual producer) is determined by the level of aggregate real balances. With sluggish price adjustment and limited monetary accommodation, the short-run response to a positive technology shock is associated with little or no change in the real money supply. Accordingly, the increase in aggregate demand (and desired output) will fall short of the increase in multifactor productivity, inducing firms to decrease the quantity of labor employed. Hence, technology shock will generate a negative correlation between employment and productivity. On the other hand, an increase in aggregate demand and output arising from a monetary expansion will be partly met by higher unobserved effort, in addition to higher "measured" employment. If the response of effort is large enough, an increase in labor productivity will ensue. In that case monetary shocks will generate a positive comovement between employment and productivity. ${ }^{3}$

An empirical evaluation of the two classes of models can exploit their different implications regarding the responses of employment and productivity to each type of shock and, as a result, the conditional correlations between employment and productivity. With that goal in mind, I attempt to identify and estimate the components of productivity and employment variations associated with technology shocks on the one hand, and non-technology shocks (demand shocks, for short) on the other. That decomposition is carried out using a structural VAR model, identified by means of a long-run restriction which is satisfied by a broad range of models, including RBC models, "newKeynesian" models (as exemplified by the model in Section 2), and even models displaying long-run effects of demand or monetary shocks. Section 3 contains a description of the empirical methodology proposed, and of its

\footnotetext{
${ }^{2}$ See Hansen and Wright (1992) for a discussion of the employment-productivity puzzle, as well as other anomalies regarding the labor market predictions of RBC models.

${ }^{3}$ See Blanchard, Solow, and Wilson (1995) for an extensive discussion of the interdependence between productivity growth and employment, in the short-run and the long-run.
} 
connection with theoretical models of the business cycle.

Section 4 presents results based on postwar U.S. data. The evidence re ported includes estimates of conditional correlations, as well as estimated impulse responses of output, employment, and productivity to technology and demand shocks. Three results stand out: (a) the estimated conditional correlations of employment and productivity are negative for technology shocks, positive for demand shocks, (b) the impulse responses show a persistent decline of employment in response to a positive technology shock, and (c) measured productivity increases temporarily in response to a positive demand shock. Those results, and many others, are shown to be robust to the labor input measure used (employment or hours), the dimension of the underlying structural VAR (a just-identified bivariate model for employment and productivity vs. a partially-identified five variable model including data on interest rates, money and prices), and the data transformation (first-differenced or HP-filtered data) on which the conditional correlation estimates are computed.

Section 5 provides some international evidence, using employment and productivity data for Canada, U.K., Germany, France, Italy, and Japan. In most cases, the results using international data largely mirror those obtained for the U.S., though a few significant differences are apparent. In particular, the three main results listed above appear to hold for every country in our sample but Japan.

Overall the evidence reported in Sections 4 and 5 seems to be clearly at odds with the predictions of standard RBC models, while being consistent with new-Keynesian models characterized by monopolistic competition, sticky prices, and variable effort.

Section 6 discusses the implications of some of the previous results for estimates of measures of short run increasing returns to labor (SRIRL) in production function regressions, and proposes an alternative approach that uses one of the series generated by the structural VAR decomposition as an instrument in one such regression. With few exceptions, the results from implementing that approach on both U.S. and international data point to the presence of significant SRIRL.

In Section 7 I plot the technology and demand components of the U.S. time series for output and employment, in order to assess their relative ability to account for the strong positive comovement of those variables that characterizes the business cycle. The verdict is clear: the fluctuations in employment and output attributed to demand shocks are (a) strongly positively 
correlated, and (b) clearly related to the main postwar cyclical episodes; neither is true for the fluctuations attributed to technology shocks.

Section 8 summarizes the main results of the paper and concludes.

\section{Labor Market Dynamics with Sticky Prices}

In this section I develop a general equilibrium monetary model with sticky prices and unobserved variations in labor effort. ${ }^{4}$ The model is deliberately stylized, in order to convey the basic point in the simplest possible way. Thus, capital accumulation is ignored, and nominal price rigidities are introduced by assuming that firms have to set their prices before shocks are realized.

\subsection{Households}

The representative household seeks to maximize

$$
E_{0} \sum_{t=0}^{\infty} \beta^{t}\left\{\log C_{t}+\lambda_{m} \log \frac{M_{t}}{P_{t}}-H\left(N_{t}, U_{t}\right)\right\}
$$

subject to the budget constraint

$$
\int_{0}^{1} P_{i t} C_{i t} d i+M_{t}=W_{t} N_{t}+V_{t} U_{t}+M_{t-1}+\Upsilon_{t}+\Pi_{t}
$$

for $t=0,1,2, \ldots . C_{t}$ is a composite consumption index defined by

$$
C_{t}=\left(\int_{0}^{1}\left(C_{i t}\right)^{\frac{\epsilon-1}{\epsilon}} d i\right)^{\frac{\epsilon}{\epsilon-1}}
$$

where $C_{i t}$ is the quantity of good $i$ consumed in period $t$. The unit price of good $i$ is given by $P_{i t}$, and

$$
P_{t}=\left(\int_{0}^{1}\left(P_{i t}\right)^{1-\epsilon} d i\right)^{\frac{1}{1-\epsilon}}
$$

\footnotetext{
${ }^{4}$ Recent examples of dynamic general equilibrium models of the business cycle with nominal rigidities include Hairault and Portier (1993), Bénassy (1995), Cho and Cooley (1995), Rotemberg (1994), King and Watson (1995), and Kim (1996). An example of business cycle models with time-varying effort ican be found in Burnside, Eichenbaum, and Rebelo (1993) for an exampl. Gordon (1990), Basu (1995), and Sbordone (1995), among others, focus on the implications of unobservable changes in labor-effort on the cyclical behavior of productivity measures.
} 
is the aggregate price index. $M$ denotes (nominal) money holdings. $H$ is disutility from work, which is a function of hours $(N)$, and effort $(U)$, and specialized to be

$$
H\left(N_{t}, U_{t}\right)=\frac{\lambda_{n}}{1+\sigma_{n}} N_{t}^{1+\sigma_{n}}+\frac{\lambda_{u}}{1+\sigma_{u}} U_{t}^{1+\sigma_{u}}
$$

$\Upsilon$ represents monetary transfers to households, and $\Pi$ denotes profits. $W$ and $V$ respectively denote the prices of an hour of work and a unit of effort. $\beta \in(0,1)$ is the discount factor. $\lambda_{m}, \lambda_{n}, \lambda_{u}, \sigma_{n}, \sigma_{u}$, are positive constants. $\epsilon>1$ is the elasticity of substitution across consumption goods. Total labor income is given by $W N+V U$. Accordingly, the "measured" hourly wage is $W+V\left(\frac{U}{N}\right)$.

We can write the first order conditions associated with the household's problem as

$$
\begin{gathered}
C_{i t}=\left(\frac{P_{i t}}{P_{t}}\right)^{-\epsilon} C_{t} \\
\frac{1}{C_{t}}=\lambda_{m} \frac{P_{t}}{M_{t}}+\beta E_{t}\left[\frac{1}{C_{t+1}} \frac{P_{t}}{P_{t+1}}\right] \\
\frac{W_{t}}{P_{t}}=\lambda_{n} C_{t} N_{t}^{\sigma_{n}} \\
\frac{V_{t}}{P_{t}}=\lambda_{u} C_{t} U_{t}^{\sigma_{u}}
\end{gathered}
$$

\subsection{Firms}

There is a continuum of firms distributed uniformly on the unit interval. Each firm is indexed by $i \in[0,1]$, and produces a differentiated good with a technology

$$
Y_{i t}=Z_{t} L_{i t}^{\alpha}
$$

$L_{i}$ may be interpreted as the quantity of effective labor input used by the firm, which is function of hours and effort:

$$
L_{i t}=N_{i t}^{\theta} U_{i t}^{1-\theta}
$$


where $\theta \in(0,1) . Z$ is an aggregate technology index, whose growth rate is assumed to follow an i.i.d. process $\left\{\eta_{t}\right\}$, with $\eta_{t} \sim N\left(0, s_{z}^{2}\right)$. Formally,

$$
Z_{t}=Z_{t-1} \exp \left(\eta_{t}\right)
$$

At the end of period $t-1$ (i.e., before the period $t$ 's realization of the money supply and technology is observed) firm $i$ sets the price $P_{i t}$ at which it will be selling good $i$ during period $t$, taking as given the prices set by other firms (and thus the aggregate price level $P_{t}$ ). Once uncertainty is realized, each firm chooses $N_{i t}$ and $U_{i t}$ optimally, given $W_{t}$ and $V_{t}{ }^{5}$ Given an output level $Y_{i t}$, cost minimization requires

$$
\frac{U_{i t}}{N_{i t}}=\left(\frac{1-\theta}{\theta}\right) \frac{W_{t}}{V_{t}}
$$

As long as the (predetermined) price $P_{i t}$ is above marginal cost ${ }^{6}$, each firm will find it optimal to meet all the demand for its product and thus choose an output level

$$
Y_{i t}=\left(\frac{P_{i t}}{P_{t}}\right)^{-\epsilon} C_{t}
$$

Thus, when setting the price the firm will seek to maximize

$$
\max _{P_{i t}} E_{t-1}\left\{\left(1 / C_{t}\right)\left(P_{i t} Y_{i t}-W_{t} N_{i t}-V_{t} U_{i t}\right)\right\}
$$

subject to (6) and (7). The corresponding first order condition is given by

$$
E_{t-1}\left\{\left(1 / C_{t}\right)\left(\alpha \theta P_{i t} Y_{i t}-\mu W_{t} N_{i t}\right)\right\}=0
$$

where $\mu \equiv \frac{\epsilon}{\epsilon-1} \cdot ?$

\footnotetext{
${ }^{5}$ Even though the level of effort is unobservable to the econometrician (and thus a potential source of productivity mismeasurement) it is assumed to be observable (and enforceable) by firms.

${ }^{6}$ As usual, that condition will hold if (a) the (ex-ante) markup is high enough and/or the size of the shocks is not too large.

${ }^{7}$ Notice that in the absence of uncertainty (8) simplifies to $P_{i t}=\mu \frac{W_{t} N_{i t}}{\alpha \theta}$, which is just the familiar optimal price condition for a monopolist facing an isoelastic demand schedule.
} 


\subsection{Money Supply}

The quantity of money $M^{s}$ in the economy is assumed to evolve according to

$$
M_{t}^{s}=M_{t-1}^{s} \exp \left(\xi_{t}+\gamma \eta_{t}\right)
$$

where $\left\{\xi_{t}\right\}$ is a white noise process orthogonal to $\left\{\eta_{t}\right\}$ (the sequence of technology shocks) at all leads and lags, and with $\xi_{t} \sim N\left(0, s_{m}^{2}\right)$. Notice that we are allowing the monetary authority to respond in a systematic fashion to technology shocks. As discussed below, such a policy may be motivated by the aim of stabilizing prices, output, or employment.

\subsection{Equilibrium}

In a symmetric equilibrium all firms will set the same price $P_{t}$ and choose identical output, hours, and effort levels $Y_{t}, N_{t}, U_{t}$. Goods market clearing requires $C_{t}=C_{i t}=Y_{i t}=Y_{t}$, for all $i \in[0,1]$, and all $t$. Equilibrium in the money market implies $\frac{M_{t}}{M_{t-1}}=\exp \left(\xi_{t}+\gamma \eta_{t}\right)$,all $t$. Using both market clearing conditions, we can rewrite (3) (after some algebraic manipulation) as

$$
C_{t}=\Phi \frac{M_{t}}{P_{t}}
$$

where $\Phi \equiv \lambda_{m}^{-1}\left[1-\beta \exp \left\{\frac{1}{2}\left(s_{m}^{2}+\gamma^{2} s_{z}^{2}\right)\right\}\right] .^{8}$

Furthermore, (4), (5), and (6) imply $U_{t}=A^{\frac{1}{\alpha(1-\theta)}} N_{t}^{\frac{1+\sigma_{n}}{1+\sigma_{u}}}$, where $A=$ $\left(\frac{\lambda_{n}(1-\theta)}{\lambda_{u} \theta}\right)^{\frac{\alpha(1-\theta)}{1+\sigma_{u}}}$. That allows us to obtain the following reduced form equilibrium relationship between output and employment:

$$
Y_{t}=A Z_{t} N_{t}^{\varphi}
$$

where $\varphi=\alpha \theta+\alpha(1-\theta)\left(\frac{1+\sigma_{n}}{1+\sigma_{u}}\right)$.

Finally, evaluating (4) and (8) at the symmetric equilibrium and combining them with (11) and (10) we can obtain a set of expressions for the equilibrium levels of prices, output, employment, and productivity, in terms

\footnotetext{
${ }^{8}$ We assume $\beta \exp \left\{\frac{1}{2}\left(s_{m}^{2}+\gamma^{2} s_{z}^{2}\right)\right\}<1$. The constant velocity associated with (10) is a consequence of our assumption of i.i.d money growth rates, which in turn implies a constant nominal rate. Though that specification simplifies the algebra considerably (leading to a simple exact solution for the equilibrium processes), most of the qualitative results emphasized below would not be affected by a more general specification.
} 
of the exogenous driving variables. Letting lower case letters denote the natural logarithm of each variable, and dropping uninteresting constants, we have:

$$
\begin{gathered}
\Delta p_{t}=\xi_{t-1}-(1-\gamma) \eta_{t-1} \\
\Delta y_{t}=\Delta \xi_{t}+\gamma \eta_{t}+(1-\gamma) \eta_{t-1} \\
n_{t}=\frac{1}{\varphi} \xi_{t}-\frac{1-\gamma}{\varphi} \eta_{t} \\
\Delta x_{t}=\left(1-\frac{1}{\varphi}\right) \Delta \xi_{t}+\left(\frac{1-\gamma}{\varphi}+\gamma\right) \eta_{t}+(1-\gamma)\left(1-\frac{1}{\varphi}\right) \eta_{t-1}
\end{gathered}
$$

where $x \equiv y-n$ denotes the log of (measured) labor productivity.

The equilibrium dynamic responses of $p, y, n$, and $x$ to each shock embodied in (12)- (15) are discussed next. We see that a monetary shock has a transitory impact on output, employment and productivity, and a permanent effect on the price level. More specifically, and in response to an unanticipated monetary expansion (i.e., a positive realization of $\xi$ ), output and employment unambiguously go up, reverting back to their original level after one period. The sign of the (also transitory) response of labor productivity $x$ depends on the size of $\varphi$, being positive if and only if $\varphi>1$. Given (11), the latter condition is easily seen to correspond to the notion of "short-run increasing returns to labor" (SRIRL) emphasized in the literature on the cyclical behavior of productivity (see, e.g., Gordon (1990)). For that condition to be satisfied in our model we require (a) sufficiently "productive" effort (low $\theta$ ), (b) a sufficiently low elasticity of effort's marginal disutility $\left(\sigma_{u}\right)$ relative to that of employment $\left(\sigma_{n}\right)$, and (c) a sufficiently high elasticity of output with respect to (effective) labor input ( $\alpha$ ). As discussed below, the possibility of a positive response of productivity to a monetary expansion plays a key role in one of the interpretations of the evidence regarding the correlation between productivity and employment. Finally, note that the only variable that will be permanently affected by the exogenous increase in the money supply will be the price level, which will adjust proportionally (though with a one period lag). 
Let us now turn to the effects of a (positive) technology shock $(\eta>0)$. Such a shock has a permanent, one-for-one effect on output and productivity, as can be seen in (13) and (15). The same shock will have a (permanent) negative effect on the price level as long as $\gamma<1$, i..e., if the degree of monetary accommodation is not too strong. Most interestingly, if the same condition is satisfied, a positive technology shock will have a negative, though transitory, effect on the level of employment. The intuition for that result is straightforward. Consider, for the sake of exposition, the $\gamma=0$ case (exogenous money). In that case, the combination of a constant money supply and predetermined prices implies that real balances (and, thus, aggregate demand) remain unchanged in the period when the technology shock occurs. Each firm will thus meet its demand by producing the same level of output. If the technology shock is positive, producing the same output will require less labor input, and a decline in employment will be observed. On the other hand, unchanged output and lower employment will lead to an unambiguous increase in labor productivity in response to the same shock. In the following period, firms adjust their prices downward (since marginal cost is lower), aggregate demand and output will go up, and employment returns to its original level. The sign of the associated change in labor productivity depends again on whether $\varphi$ is greater or less than one (i.e., on whether the change in output is more or less than proportional to the change in hours), which, in turn, determines whether the immediate response of productivity to a technology shock overshoots or not its long run level.

Needless to say, the sign of the short run employment response to a technology shock stands in stark contrast with the predictions of standard calibrated RBC models, which imply a response of employment of the same sign as the underlying technology shock ${ }^{9}$.

By looking at (12)- (15) it should be clear that the qualitative effects of a technology shock described above will remain unchanged in the presence of an endogenous monetary response, so long as $\gamma \in[0,1)$, a parameter range

\footnotetext{
${ }^{9}$ Nonstandard specifications of calibrated RBC models characterized by slow technology diffusion often predict a negative response of employment to a positive technology shock (see, e.g., Hairault, Langot, and Portier (1995), Cooley and Dwyer (1995)). In those models a positive technology shock induces a small rightward shift in labor demand, which is more than offset by a relatively larger leftward shift in labor supply (resulting from the wealth effect), thus leading to a short-run decline in employment. That mechanism is unrelated to the mechanism at work in the present model and, at least in this author's view, little plausible.
} 
which includes both exogenous monetary policy as well as monetary rule aimed at smoothing price and output changes. More generally, the choice of the policy rule will only have a permanent effect on prices, but it will affect the size and/or the dynamic pattern of the responses of output, employment and productivity. In particular, the monetary authority will face a trade off between employment and price volatility on the one hand, and the magnitude of unanticipated output changes on the other. ${ }^{10}$

The unconditional covariances among the growth rates of output, labor productivity, employment implied by the above stylized model are given by

$$
\begin{gathered}
\operatorname{cov}\left(\Delta y_{t}, \Delta n_{t}\right)=\frac{1}{\varphi}\left(2 s_{m}^{2}+(1-\gamma)(1-2 \gamma) s_{z}^{2}\right) \\
\operatorname{cov}\left(\Delta y_{t}, \Delta x_{t}\right)=\frac{1}{\varphi}\left(2(\varphi-1) s_{m}^{2}+(\gamma+\varphi-1) s_{z}^{2}\right) \\
\operatorname{cov}\left(\Delta n_{t}, \Delta x_{t}\right)=\left(\frac{1}{\varphi}\right)^{2}\left(2(\varphi-1) s_{m}^{2}-(1-\gamma)[(2-\varphi)+2 \gamma(\varphi-1)] s_{z}^{2}\right)
\end{gathered}
$$

Whenever $\gamma \in\left[0, \frac{1}{2}\right)$ and/or exogenous monetary shocks are a sufficiently important source of fluctuations (relative to technology) the model predicts that employment growth should be procyclical-a property which is a robust feature of the data. Furthermore, $\varphi>1$ is a sufficient condition for measured labor productivity to be procyclical-another feature of the dataindependently of the relative importance of the two shocks.

The sign of the comovement between employment and productivity growththe focus of our attention-depends on the size of $\varphi$, the policy parameter $\gamma$, and the relative importance of shocks. It is useful to look first at the sign of the conditional covariances, $\operatorname{cov}_{z}\left(\Delta n_{t}, \Delta x_{t}\right)$ and $\operatorname{cov}_{m}\left(\Delta n_{t}, \Delta x_{t}\right)$. Thus, and conditional on technology being the only source of fluctuations, we have

$$
\operatorname{cov}_{z}\left(\Delta n_{t}, \Delta x_{t}\right)=-\frac{(1-\gamma)}{\varphi^{2}}[(2-\varphi)+2 \gamma(\varphi-1)] s_{z}^{2}
$$

Under the assumptions $\gamma \in[0,1)$ and $\varphi \in(1,2)$ it is easy to check that $\operatorname{cov}_{z}\left(\Delta n_{t}, \Delta x_{t}\right)<0$, i.e., technology shocks generate a negative comovement

\footnotetext{
${ }^{10}$ Notice that, in particular, the central bank could set $\gamma=1$ and $s_{m}^{2}=0$, in which case the equilibrium response of output and employment would correspond to that in the equilibrium with fully flexible prices.
} 
between employment and productivity growth. As argued above those assumptions are indeed quite plausible empirically. Section 5 below provides further evidence supporting a value for $\varphi$ in the assumed range.

On the other hand,

$$
\operatorname{cov}_{m}\left(\Delta n_{t}, \Delta x_{t}\right)=\frac{2(\varphi-1)}{\varphi^{2}} s_{m}^{2}
$$

whose sign is determined by the sign of $\varphi-1$. If SRIRL are present, monetary shocks will generate a positive comovement between employment and productivity growth.

The case of most interest-and a plausible one, in our view-corresponds to $\varphi \in(1,2)$, and $\gamma \in[0,1)$, i.e., it combines some SRIRL with a not-toostrong endogenous money response. In that case the model's predictions regarding the signs of the unconditional comovements among output, employment, and productivity are consistent with the evidence, and not unlike the predictions of the standard RBC model. Yet, under the same assumptions, the two models imply conditional comovements between employment and productivity growth of opposite signs: conditional on monetary (nontechnology) shocks being the source of fluctuations, the sticky price model predicts a positive correlation between employment and productivity growth, whereas the corresponding comovement conditional on technology shocks is negative. That prediction is in stark contrast with the prediction of standard RBC models with multiple shocks where, for the reasons described in the introduction, technology shocks are a source of a positive comovement between employment and productivity, while non-technology shocks generate a negative comovement (see, e.g., Christiano and Eichenbaum (1992)).

\section{An Empirical Model}

In the previous section I analyzed a stylized model of an economy with imperfect competition, short-run nominal rigidities, and variable effort, subject to both technology and non-technology (monetary) disturbances. Under certain assumptions, that model was shown to be consistent with the observed lack of correlation between employment and productivity growth. As is well known, a standard RBC model driven by multiple shocks can also potentially account for that near-zero correlation. The two classes of models have, however, very different implication regarding the responses of employment 
and productivity to each type of shock and, as a result, on the conditional correlations between employment and productivity growth.

In this section I attempt to identify and estimate the components of productivity and employment variations associated with technology on the one hand, and non-technology shocks (demand shocks, for short) on the other. That decomposition is carried out using a structural VAR model, identified by means of a long-run restriction which is satisfied by a broad range of models, including RBC models and models with nominal rigidities. Given estimates of each component of employment and productivity variations we can compute the corresponding conditional correlations (and other second moments) which can be contrasted with the different models' predictions.

\subsection{A General Framework}

Next I discuss the assumptions underlying my identification strategy. Those assumptions implicitly determine the range of models which the empirical framework below can embrace. First, I assume an aggregate production function

$$
Y_{t}=F\left(K_{t}, Z_{t} L_{t}\right)
$$

where $Y$ is output, $K$ and $L$ denote the effective capital and labor input services employed (thus allowing for possible unobservable variations in the utilization rate of both inputs), and $Z$ is an exogenous technology parameter. $F$ is assumed to be homogeneous of degree one. Technology evolves according to $Z_{t}=Z_{t-1} \exp \left(\delta+\eta_{t}\right)$, where $A(L) \eta_{t}=\varepsilon_{t}^{z}$, with $A(0)=1$, and $A(x) \neq 0$, for all $|x| \leq 1$. In words, the growth rate of $Z$ is assumed to follow a stationary autoregressive process with mean $\delta$.

Let $r_{i t}$ denote the one-period return on an asset $i$ held between $t-1$ and $t$. I assume that the sequence of returns $\left\{r_{i t}\right\}$ is a stationary stochastic process, for all $i$. That assumption is backed by the observed time series properties of returns on financial assets and, in particular, by the evidence of stationarity in real interest rates presented below. ${ }^{11}$ This must also be true for physical

\footnotetext{
${ }^{11}$ The evidence on stock returns points to small departures from white noise (see, e.g., Singleton (1990)). The evidence on real interest rates is less robust, but generally tends to reject the presence of a unit root (see, e.g., Mishkin (1992)). Under the maintained assumption of a constant time discount rate, the evidence suggests that the possible variations in the wedge between consumers' intertemporal marginal rates of substitution and
} 
capital, whose return (say, $r_{t}$ ) is given by the first order condition associated with profit maximization

$$
\begin{aligned}
r_{t} & =F_{K}\left(K_{t}, Z_{t} L_{t}\right)+\nu_{t} \\
& =f^{\prime}\left(\frac{K_{t}}{Z_{t} L_{t}}\right)+\nu_{t}
\end{aligned}
$$

where $f^{\prime}(\cdot) \equiv F_{K}(\cdot, 1)$ denotes the marginal product of capital, and $\nu_{t}$ accounts for the possible existence of (possibly stochastic) depreciation, adjustment costs, departures from perfect competition, etc. $\left\{\nu_{t}\right\}$ is assumed to follow a stationary stochastic process (possibly with a nonzero mean) ${ }^{12}$.

Effective labor input $L_{t}$ is assumed to be a function of employment and unobserved effort. Formally,

$$
L_{t}=g\left(N_{t}, U_{t}\right)
$$

where $g$ is homogeneous of degree one. I assume that effort per worker (or per worker-hour) $\left\{\frac{U_{t}}{N_{t}}\right\}$ is a stationary stochastic process. In addition to its plausibility, the latter property is consistent with most business cycle models that allow for effort variation (e.g., Burnside et al. (1995), Sbordone (1995)).

By combining (19), (20), and (22) we can derive the following expression for measured labor productivity $X_{t}=\frac{Y_{t}}{N_{t}}=\frac{Y_{t}}{L_{t}} \frac{L_{t}}{N_{t}}=Z_{t} F\left(\omega_{t}, 1\right) g\left(1, \frac{U_{t}}{N_{t}}\right)$, where $\omega_{t}=f^{\prime-1}\left(r_{t}-\nu_{t}\right)$. Letting $\zeta_{t} \equiv \log \left(F\left(\omega_{t} ; 1\right) g\left(1, \frac{U_{t}}{N_{t}}\right)\right)$, we can rewrite the previous equation as

$$
x_{t}=z_{t}+\zeta_{t}
$$

where, given the assumptions of stationarity of $r_{t}, v_{t}$, and $\frac{U_{t}}{N_{t}}$ made above, $\left\{\zeta_{t}\right\}$ is stationary.

Equation (23) holds the key to identification of technology shocks in our framework, for it implies that only permanent changes in the stochastic component of the technology parameter $z$ can be the source of a unit root in productivity. Put it differently, while all types of exogenous shocks impinging on

asset returns (e.g., a capital income tax rate) are not well characterized by a unit root process, for such a unit root would in that case be inherited by the proces for before-tax asset returns.

${ }^{12}$ Notice that the standard case with no adjustment costs, and perfect competition corresponds to a constant $\nu_{t}=\nu$, equal to (minus) the depreciation rate. 
the economy can affect labor productivity temporarily-through their effects on effort per worker and the effective capital/labor ratio - only technology shocks can have a permanent effect on the level of labor productivity.

Notice that the above framework allows for non-technology shocks that may have permanent effects on the levels of employment and output. Examples of models where those effects could be found include RBC models with non-stationary government spending, models which combine monetary non-neutralities with labor market features that generate hysteresis in employment, and models with permanent labor supply shocks. Thus, my identifying restriction is weaker than the one originally proposed by Blanchard and Quah (1989), and which restricted demand shocks not to have permanent effects on the levels of output (and, at least implicitly, employment). ${ }^{13}$

\subsection{Specification and Identification}

In a general aggregative framework, the assumptions of constant returns and stationarity of asset returns and effort have been shown to imply that the unit root in measured labor productivity must be associated with the presence of permanent technology shocks. The ability of the empirical model developed below to sort out the effects of technology and non-technology shocks hinges critically on the presence of such a unit root, so we need to check whether it can be found in the data. By contrast, the same framework is silent regarding the order of integration of employment, which in a fully specified model would be affected by agents' preferences, labor market structure, and the nature of shocks impinging on the economy, as discussed above. Yet, and in order to specify the empirical model correctly, we need to take a stand on the order of integration of employment. The results of a battery of unit root tests on data for the G7 countries, reported and discussed below, strongly suggest that the three time series we are mostly concerned with here (output, employment and productivity) are reasonably characterized as being generated by I(1) processes.

\footnotetext{
${ }^{13}$ Notice that, in contrast with Shapiro and Watson (1988), my identifying assumption allows one to disentagle technology shocks from (permanent) labor supply shocks without having to impose the assumption that technology shocks have no long run effect on labor supply. Though with a different motivation and objectives, the identification strategy adopted here is closer to that in Gamber and Joutz (1993), who restrict labor supply shocks not to have a permanent effect on real wages, while allowing technology shocks to have such a permanent effect.
} 
Motivated by that evidence, the empirical analysis below proceeds under the assumption that $\left\{\left(x_{t}, n_{t}\right)\right\} \equiv\left\{q_{t}\right\}$ is a bivariate $I(1)$ process, with a stationary VAR representation in first differences. The observed variations in measures of productivity and employment (and thus in $q_{t}$ ) are interpreted as originating in two types of exogenous disturbances-technology and demand shocks-, which are orthogonal to each other, and whose impact is propagated over time to employment and output through various unspecified mechanisms. We represent that idea formally by assuming that $\left\{\Delta q_{t}\right\}$ can be expressed as a (possibly infinite) distributed lag of both types of disturbances:

$$
\Delta q_{t}=\left[\begin{array}{ll}
C^{11}(L) & C^{12}(L) \\
C^{21}(L) & C^{22}(L)
\end{array}\right] \varepsilon_{t}=C(L) \varepsilon_{t}
$$

where $\varepsilon_{t}=\left[\varepsilon_{t}^{z}, \varepsilon_{t}^{m}\right]^{\prime}$ is a vector whose elements are period $t$ 's technology $\left(\varepsilon_{t}^{z}\right)$ and demand shocks $\left(\varepsilon_{t}^{m}\right)$. The orthogonality assumption (combined with a scale normalization) implies $E \varepsilon_{t} \varepsilon_{t}^{\prime}=I$. Furthermore, the restrictionimplied by the general framework discussed above-that the unit root in productivity originates exclusively in technology shocks corresponds to $C^{12}(1)=$ 0 . In other words, the matrix of long-run multipliers $C(1)$ is constrained to be lower triangular.

Let the reduced form VAR representation for $\left\{\Delta q_{t}\right\}$ be given by

$$
B(L) \Delta q_{t}=\nu_{t}
$$

where $B(0) \equiv I, E \nu_{t} \nu_{t}^{\prime}=\Sigma$, and $E \nu_{t} \Delta x_{t-j}=0$, for $j=1,2,3, \ldots$. We further require that each reduced form innovation is an (independent) linear combination of the structural shocks, i.e., $\nu_{t}=S \epsilon_{t}$ for some nonsingular matrix $S$, a condition that guarantees that the structural shocks are fundamental.

Under the previous assumptions one can show $C(1)$ is the Choleski factor of $E(1) \Sigma E(1)^{\prime}$, where $E(L) \equiv B(L)^{-1}$. Given consistent estimates for $E(L)$ and $\Sigma$, the matrix of impulse responses $C(L)$ can be estimated using

$$
\begin{aligned}
C(L) & =E(L) S \\
& =E(L) E(1)^{-1} C(1)
\end{aligned}
$$

The components of productivity growth associated with technology and demand shocks are respectively given by 


$$
\begin{aligned}
\Delta x_{t}^{z} & =C^{11}(L) \Pi^{1}(L) \Delta q_{t} \\
\Delta x_{t}^{m} & =C^{12}(L) \Pi^{2}(L) \Delta q_{t}
\end{aligned}
$$

where $\Pi^{i}(L) \equiv e_{i}^{\prime} E(1)^{-1} C(1) B(L)$, for $i=1,2$, with $e_{i}$ denoting the $i$ th column of a (2x2) identity matrix.

The corresponding components of (log) employment are

$$
\begin{aligned}
\Delta n_{t}^{z} & =C^{21}(L) \Pi^{1}(L) \Delta q_{t} \\
\Delta n_{t}^{m} & =C^{22}(L) \Pi^{2}(L) \Delta q_{t}
\end{aligned}
$$

Given a time series for each component of employment and productivity growth, their conditional correlations $-\rho_{z}\left(\Delta n_{t}, \Delta x_{t}\right)$ and $\rho_{m}\left(\Delta n_{t}, \Delta x_{t}\right)$ - can be consistently estimated using the sample correlations $\widehat{\rho}\left(\Delta n_{t}^{z}, \Delta x_{t}^{z}\right) \equiv \hat{\rho}_{z}$, and $\widehat{\rho}\left(\Delta n_{t}^{m}, \Delta x_{t}^{m}\right) \equiv \widehat{\rho}_{m}$.

In addition to the two previous comovement estimates, the empirical section below also reports the sample correlations between the time series obtained as the residual after applying an Hodrick-Prescott filter to $n_{t}^{i}$ and $x_{t}^{i}$, for $i=z, m$, i.e., to the (log) levels of each component of employment and productivity. We denote the resulting detrended series by $\left\{\widehat{x}_{t}^{i}, \widehat{n}_{t}^{i}\right\}$ for $i=z, m$.

\section{Evidence for the U.S. Economy}

\subsection{Benchmark Results}

\subsubsection{Data and Unit Root Tests}

Our benchmark results rely on estimates of a structural VAR for labor input and productivity measures, using U.S. quarterly data covering the period 48:1-94:4. Two alternative labor input series, drawn from Citibase, are used: the $(\log )$ employed civilian labor force,denoted by $n_{e}$, and (log) total employee-hours in non-agricultural establishments, denoted by $n_{h}$. Two alternative time series for (log) productivity, denoted by $x_{e}$ and $x_{h}$, are constructed as the difference between $(\log )$ GDP $(y)$ and the corresponding labor input measure. 
The first panel of Table 1 reports the results of Augmented Dickey Fuller (ADF) unit root tests applied to the levels and first differences of the time series just introduced. The test fails to reject the null of a unit root in the levels of all the series, but it does reject the same null when applied to their first differences. Those results suggest that we characterize $\left\{[x, n]^{\prime}\right\}$ as an $I(1)$ process (regardless of whether hours or employment is used), thus motivating the VAR specification introduced above.

\subsubsection{Estimates of Conditional Correlations}

The main results of this section are reported in the first two panels of Table 2. For each combination of labor input measures and detrending filter, the first panel ("Data") reports the estimate of the unconditional correlation of employment and productivity $(\widehat{\rho})$, while the second panel ("Bivariate") reports the estimated correlations of their technology-driven components $\left(\hat{\rho}_{z}\right)$, and their demand-driven components $\left(\hat{\rho}_{m}\right)$. That evidence is supplemented with Figures $2 \mathrm{a}$ and $2 \mathrm{~b}$, which display scatterplots of the original labor input and productivity series, as well as scatterplots of their components.

Estimates the unconditional correlation of employment and productivity is are small and, with one exception, negative, its values ranging from -0.29 to 0.28 , and an average of -0.14 . As argued in the introduction, the absence of a large positive correlation between employment and productivity is in conflict with a key prediction of standard calibrated RBC models in which equilibrium fluctuations are driven by technology shocks, but can in principle be reconciled with multiple-shock versions of those models, since non-technology shocks lead to a negative correlation between employment and productivity that may offset the positive comovement induced by technology shocks. Our benchmark estimates of the conditional correlations are, however, inconsistent with that hypothesis: in all cases, the estimates point to a large, negative correlation between the technology-driven components of employment and productivity growth (average estimate $=-0.78$ ), whereas the corresponding demand-driven components display a positive correlation (average estimate $=0.38$ ), as reported in the second and third columns of Table 2.

The previous results are, on the other hand, consistent with the predictions of models with imperfect competition, sticky prices, and variable effort, as exemplified by the stylized model developed in Section 2. As shown there, the short term rigidity in aggregate demand resulting from the stickiness of 
the price level (and the lack of a sufficiently accommodating monetary policy) leads technology shocks to generate a negative comovement between employment and productivity, while unobserved effort variations are responsible for the positive comovement between the same variables generated by demand shocks.

\subsubsection{Impulse Responses}

In order to understand the source of the previous results it is useful to look at the estimated dynamic responses of productivity, output, and employment to each type of shock. Those responses are respectively given by the coefficients of the polynomials $C^{1 i}(L), C^{1 i}(L)+C^{2 i}(L)$, and $C^{2 i}(L)$, with $i=1$ for a technology shock, and $i=2$ in the case of a demand shock. Figures 3.a. and 3.b. report the estimated impulse responses (darker bars), when hours (Figure 3.a.) or employment (Figure 3.b.) The lighter bars represent a \pm two standard deviation confidence interval for the null hypothesis that the impulse response is flat at zero.

Regardless of whether hours or employment are used as a labor input measure, the qualitative patterns observed in the estimated impulse responses are very similar. In response to a positive one standard deviation-sized technology shock, labor productivity experiences an increase of about $0.6 \%$, eventually stabilizing at a level somewhat higher. Output also experiences a permanent increase, but the initial rise appears to be more gradual than in the productivity case. The gap between the initial increase in labor productivity and the (smaller) increase in output is reflected in a short-lived, though persistent, decline in employment. The fact that the bulk of the joint variation in employment and productivity arising from a technology shock, takes place at impact, with both variables moving in opposite directions, is responsible for the overall negative conditional correlation between the two variables reported above. ${ }^{14}$

\footnotetext{
${ }^{14} \mathrm{~A}$ decline in employment (or, alternatively, an increase in unemployment) resulting from a positive technology shock can also be detected in the a number of structural VARs (characterized by different identification schemes) in the recent literature. Since the purpose of those exercises is generally unrelated to the issue at stake here, the presence of such a result often appears to go unnoticed or, at most, is briefly mentioned in the text. Among the papers where that result can be found we have: Blanchard and Quah (1989, Figure 6), Gamber and Joutz (1993, figure 1), Cooley and Dwyer (1995, Figure 1), and Forni and Reichlin (1995, Figure 3) and Blanchard (1989, Figure 1.b.), and Blanchard, Solow and Wilson (1995, Figures $\mathrm{C}$ and D). The latter two papers provide a longer discussion of the
} 
Figures 3.a.and 3.b. also display the estimated dynamic responses to a demand shock, as identified by the empirical framework above. A positive one standard deviation shock to demand is shown to have a large, and persistent effect on output, employment, and productivity. Interestingly, while the effect on productivity vanishes over time (by construction) the shock has a sizable permanent impact on both employment and output, thus emerging as the main source of the unit root detected in the labor input measures. As in the case of the technology shock, the positive comovement of employment and productivity in the period the shock hits the economy dominates the estimated conditional correlation, accounting for the positive sign of the estimated conditional correlation reported in Table 2.

\subsection{Results from a Five Variable VAR Model}

The evidence just discussed relies on an empirical model which assumes that all observed variations in labor input and productivity are the result of two types of shocks, which I have labeled as technology and demand. If, in fact, there are more than two independent sources of fluctuations with "sufficiently different" dynamic effect son the variables considered the above model will be misspecified, and the associated decomposition and impulse responses of little use. $^{15}$ Without meaning to take a stand here on what the relevant number of shocks is, and purely as a check on the robustness of the results presented above I have also estimated a higher dimensional (five variable) VAR model, which allows for four independent demand shocks-still identified as shocks that do not have a permanent effect on the level of productivity. Even though I make no attempt to identify each of demand shocks separately (which would require imposing additional restrictions), the estimated model still provides interesting information regarding the effects of technology shocks on a larger number of variables than was the case for the small VAR.

\subsubsection{Specification}

The specification considered uses data on money, interest rates, and prices, in addition to the productivity and labor input series discussed above. My measure of the stock of money, denoted by $m$, is the $(\log )$ of M2. The price

finding, interpreting it as being consistent with the traditional Keynesian model.

${ }^{15}$ A discussion of what is precisely meant by "similar" dynamic responses across disturbances can be found in the appendix to Blanchard and Quah (1989). 
measure $(p)$ is the $(\log )$ of the CPI. The nominal interest rate measure $(r)$ is the three-month Treasury Bill rate. Because of limited data availability for M2 the sample period for this specification is 59:1-94:4 . Results of unit root tests applied to the previous time series, reported in the panel (b) of Table 1, suggest that both money growth $(\Delta m)$ and inflation $(\Delta p)$ can be thought of as cointegrated $I(1)$ processes with cointegrating vector $[1,-1]$, implying a stationary process for the rate of growth of real balances, $\left\{\Delta m_{t}-\Delta p_{t}\right\}$. Analogous properties also seem to hold for the nominal rate $r$ and inflation $\Delta p$, implying a stationary (ex-post) real interest rate process $\left\{r-\Delta p_{t+1}\right\}$. This lead us to consider the moving average model $\Delta q_{t}=$ $C(L) \varepsilon_{t}$, where $\Delta q_{t} \equiv\left[\Delta x_{t}, \Delta n_{t}, \Delta m_{t}-\Delta p_{t}, r_{t}-\Delta p_{t}, \Delta^{2} p_{t}\right]^{\prime}$, and $\varepsilon_{t} \equiv$ $\left[\varepsilon_{t}^{z}, \varepsilon_{t}^{m_{1}}, \varepsilon_{t}^{m_{2}}, \varepsilon_{t}^{m_{3}}, \varepsilon_{t}^{m_{4}}\right]^{\prime}$. In order to identify technology shocks we assume $E \varepsilon_{t}^{z} \varepsilon_{t}^{m_{j}}=0$, and (using obvious notation) $C^{1 j}(1)=0$, for $j=2,3,4,5$. In words, technology shocks $\left\{\varepsilon_{t}^{z}\right\}$ are assumed to orthogonal to demand shocks, as well as the only source of the unit root in productivity. ${ }^{16}$

\subsubsection{Conditional Correlations}

The last pair of columns in Table 2 ("Large VAR"), displays the estimated conditional correlations of productivity and employment based on the five variable model described above, for each combination of labor input and data transformation. Across the board, the estimates point to the same phenomenon picked up in the bivariate model: the technology-driven component of productivity and employment are negatively correlated, whereas the corresponding demand-driven component (i.e., the sum of the components associated with the four different non-technology shocks allowed for) is positively correlated.

\subsubsection{Impulse Responses}

Figures 4.a. and 4.b. display the impulse responses of a number of variables to a technology shock, using hours (4.a.) or employment (4.b.) as a labor input measure. The pattern of responses of productivity, output, and employment is very similar to that obtained from the small VAR: a positive technology shock leads to an immediate increase in productivity that is not

\footnotetext{
${ }^{16}$ In separate tests (not reported), I was unable to establish cointegration among $x$, $n, m-p$, and $\Delta p$, thus justifying the first-difference transformation of those variables that is used in the final specification.
} 
matched by a proportional change in output (the latter's response building up more slowly over time), implying a (largely) transitory but persistent (and quantitatively nonnegligible) decline in employment. Two small differences may be worth pointing. first, when the hours series is used (but not when I use employment) the estimated output response shows a small (and hardly significant) decline in output in the short run, which is not easily explainable with the framework laid out in section 2 (though one can always come up with some stories). Secondly, the initial negative effect of the technology shock on labor input is now more than fully reversed over time (regardless of the labor input measure used), leading to a positive, though quantitatively small, long term effect.

Notice that the gradual response of output parallels the slow build-up of real balances over time. The latter, in turn, results from the combination of moderate but persistent deflation and positive money growth. Though not shown explicitly in the Figure, velocity $(m-p-y)$ is persistently higher after the shock, which is consistent with the observed decline in the nominal rate. Finally, and because of movements of identical sign and similar magnitude in the nominal rate and inflation, the response of the (ex-ante) real rate $\left(r-\Delta p_{+1}\right)$ is largely insignificant, with the exception of the substantial increase at impact under the specification using hours. Though alternative interpretations may be possible, I view the joint response of those variables as being largely consistent with the hypothesis of sluggish price adjustment, and a monetary response that works in the direction of stabilizing prices and employment, but which falls well short of achieving that stability. ${ }^{17}$

\section{International Evidence}

In this section I report evidence on the correlations of productivity and employment based on data for the remaining G7 countries: Canada, U.K., Germany, France, Italy, and France. ${ }^{18}$ For each country I have estimated a bivariate VAR model identical to the one underlying the benchmark results

\footnotetext{
${ }^{17}$ In the context of the sticky price model developed above, avoiding the decline in employment requires a more expansionary monetary stance, the latter being necessary to generated sufficient demand in the short-run to absorb an increase in output proportional to the increase in multifactor productivity, without the need for the slow price adjustment actually observed.

${ }^{18}$ Evidence for Spain using a related approach can be found in Galí (1996).
} 
for the U.S., but limited to a single specification that uses employment as a labor input measure. My data set includes the time series for the (log) employed civilian labor force as a measure of employment, (log) GDP as the output measure, and a series for $(\log )$ labor productivity (constructed with the other two). All data are quarterly, and seasonally adjusted. Sample periods vary across countries, depending on data availability. ${ }^{19}$

Table 3 reports the results of ADF unit root tests on the levels and first differences of the time series considered. With a few exceptions the test results point to the presence of a unit root in the levels of employment, productivity and output series, but they tend to reject a unit root in their first differences (at a 5\% significance level). The exceptions lie in the results for some of the employment series. Thus, for France the test rejects a unit root in $n$, a result that leads me to adjust the VAR specification accordingly for that country. On the other hand, U.K., Germany, and Italy I cannot reject (marginally) the null of a unit root in $\Delta n$. The latter result, however, is likely to reflect the low power of the test, since it is not consistent with the parallel rejection of a unit root in $\Delta y$ and $\Delta x$ in the same countries. Most importantly for my identification strategy, the characterization of the productivity series as being integrated of order one holds in each of the six countries considered.

For each country, Table 4 reports (under the heading $\hat{\rho}$ ) the unconditional correlation of employment and productivity. When first differences of those variables are used, the correlations are very small in absolute value, with the exception of Italy, where it is -0.47 . The average correlation is -0.14 . The results for the HP-filtered series are not too different, though now the outlier is France with a 0.29 correlation value. The average correlation for the HP filtered series is 0.02 . Overall, and in accordance with the estimates based on U.S. data, there is clearly no evidence of the large positive correlations of productivity and employment predicted by flexible price, technology-driven RBC models.

The remaining two columns in each country's panel $\left(\hat{\rho}_{z}\right.$ and $\left.\hat{\rho}_{m}\right)$ report the estimated conditional correlations, based on a just-identified VAR model for $[\Delta x, \Delta n]^{\prime}$ analogous to the one underlying the benchmark results for the

\footnotetext{
${ }^{19}$ Sample periods: U.S. (54:1-94:4), Canada (62:1-94:4), U.K. (62:1-94:3), Germany (70:1-94:4), France (70:1-94:4), Italy (70:1-94:3), and Japan (62:1-94:4). Employment data are drawn from OECD Quarterly Labor Force statistics. GDP data are taken from the OECD Quarterly National Income Accounts.
} 
U.S.. ${ }^{20}$ When the correlations are computed using first differences, in five out of six countries (Japan being the outlier) the estimates point to a negative correlation between the technology components of employment and productivity, with the corresponding demand-driven components showing a positive correlation. The signs of those correlations is reversed for Japan. When the $(\log )$ levels of the estimated components of the series are transformed using the HP-filter the pattern of correlation signs remains largely unchanged, though now both conditional correlations have a positive sign in Canada and Japan.

Figures 5.a.-5.f. display the corresponding impulse responses of productivity, output, and employment to a technology and demand shocks, for the six countries considered in this section. With the exception of Japan, the patterns of responses to the two shocks are not too different from the U.S., though a few differences can be detected. Among the latter, perhaps the most interesting lies in the much stronger persistence and negative permanent effects of a positive technology shock on employment, in three European countries (UK, Germany, and Italy). By way of contrast, in Canada the short run negative impact on employment is fully reversed by the third quarter after the shock, and ends up having a strong positive effect asymptotically. The dynamic responses to a demand shock seem to be quite similar across the board (with the exception of Japan), and close to those obtained for the U.S. On the other hand, the estimated impulse responses for Japan seem to accord better with the predictions of standard RBC models, with the response of employment, output and productivity to a positive technology shock is very weak in the short run, and only builds up (eventually stabilizing at a different level) as the horizon increases, and negative (though insignificant) impact of a positive demand shock on productivity.

\section{Estimates of SRIRL}

The decomposition of the output and employment time series into their demand and technology-driven components allow us to estimate a version of

\footnotetext{
${ }^{20}$ Motivated by the results of unit root tests, the estimated VAR for France included the $(\log )$ level of employment (and a time trend as an additional regressor), instead of the employment growth rate. Yet, and for the sake of comparability with other countries, all the correlation estimates for France were based on either a first-difference or HP transformation of the relevent series.
} 
the reduced form production function (11). ${ }^{21}$ The latter is rewritten here in (log) first-differences as:

$$
\Delta y_{t}=\delta+\varphi \Delta n_{t}+u_{t}
$$

where $u_{t} \equiv \Delta z_{t}-\delta$, and $\delta \equiv E\left(\Delta z_{t}\right)$. It is important to emphasize that in the context of the model above, $\varphi$ is a "reduced form" parameter, which captures, in addition to the hours-elasticity of output, the effect associated with unmeasured variations effort that accompany movements in hours in equilibrium.

The difficulties associated with estimation of (26) given raw output and employment data are well known. They stem from the potential correlation between the error term $\Delta z_{t}$ and the regressor $\Delta n_{t}$, as well as the unrestricted serial correlation in $\Delta z_{t}{ }^{22}$ In particular, estimates of $\varphi$ obtained with OLS are generally believed to be biased upward, since the error term is presumed to be positively correlated with the regressor. Interestingly, some of the empirical evidence reported above calls that presumption into question, by raising the possibility that $\Delta z_{t}$ and $\Delta n_{t}$ might be negatively correlated, in which case OLS estimates of $\varphi$ would be downward biased.

Furthermore, the empirical model used to identify and estimate the effects of technology shocks may also provide a means to overcome the simultaneity problem that lies at the root of the inconsistency of the OLS estimator, without having to rely on often poor and somewhat ad-hoc instruments. To see this, notice that one can rewrite (26) as

$$
\Delta y_{t}=\delta+\varphi \Delta n_{t}^{m}+\tilde{u}_{t}
$$

where $\widetilde{u}_{t} \equiv \varphi \Delta n_{t}^{m}+\Delta z_{t}-\delta$, and where $\left\{\Delta n_{t}^{m}\right\}$ represents the time series for the demand component of employment variations generated by the structural VAR decomposition in the previous section. Conditional on our identification being correct, $\Delta n^{m}$ is orthogonal to $\Delta z$ at all leads and lags, thus making it possible to estimate $\varphi$ consistently by applying OLS to (27) ${ }^{23}$ In other words,

\footnotetext{
${ }^{21}$ The exercise in this section was suggested by Bill Brainard.

${ }^{22}$ The latter rules out using the lagged values of any (potentially) endogenous variable as an instrument.

${ }^{23}$ The fact that we do not observe $\left\{\Delta n_{t}^{m}\right\}$ directly but need to rely on a constructed series based on our estimates implies that both variables in the regression are measured with error in small samples. Though the latter vanishes asymptotically (given the consistency of our procedure), our estimates of $\varphi$ will be subject to small sample bias.
} 
the structural VAR exercise is used to generate an "artificial" variable which is, by construction, an appropriate instrument for employment variations in a production function regression.

Table 4 reports several estimates of $\varphi$ for the U.S. economy, using both hours and employment data. In all cases "robust" standard errors are reported in brackets. The first column ("OLS") reports the estimates of $\varphi$ resulting from applying OLS to (26). In a way consistent with other authors' analogous regressions the resulting $\varphi$ estimates are substantially higher than the observed labor income share. Interpretations of that finding as evidence of increasing returns, market power, and/or variable effort are generally muted by the possibility of substantial bias, as mentioned above. ${ }^{24}$

The second and third columns report estimates for $\varphi$ using as a regressor the series for $\Delta n^{m}$ generated by the bivariate and five-variable models, respectively. In all cases the point estimates are significantly above one, thus suggesting the presence of substantial increasing return to labor, possibly due to procyclical fluctuations in unobserved effort. ${ }^{25}$

Table 5 presents similar evidence based on international data. In this case the original OLS estimates of $\varphi$, using actual employment changes as a regressor, show considerable variation across countries, ranging from 0.33 in Italy to1.15 in Germany. The average point estimate is 0.81 . Yet, the corrected point estimates (using the demand component of employment changes) are above one for all countries but Japan, though both in Canada and Italy they are insignificantly different from one. The average point estimate is 1.26 (and as high as 1.41 if we exclude Japan).

Thus, our results point to the presence of substantial short run increasing returns to labor (SRIRL) for all countries in our sample, with the exception of Japan. Since values of $\varphi$ greater than one correspond to positive comovements of employment and (measured) labor productivity in response to demand disturbances, the previous estimates mirror the estimates of conditional correlations found in Table 4, where Japan also stood out as an exception.

\footnotetext{
${ }^{24}$ See Burnside (1996) for a useful overview of that literature, as well as some additional findings.

${ }^{25}$ The fact that the estimates using employment as a labor input measure are systematically higher than the ones based on hours should not be surprising, given the positive correlation between employment and hours per worker.
} 


\section{Do Technology Shocks Generate (Recog- nizable) Business Cycles...?}

A central feature of business cycles is the strong, positive comovement in GNP and labor input measures. That property, which has been documented extensively, appears to hold for all industrialized countries, and is robust to the specific data series and/or detrending methods used. Any theory of business cycles which failed to capture that feature would be viewed as empirically irrelevant and would arise little attention from the profession, so it is thus not surprising that a high, positive output-employment correlation lies among the key predictions of equilibrium business cycle models driven by technology shocks. Yet, whether technology shocks in actual economies are responsible for the pattern of output and employment fluctuations associated with business cycles remains an open question, and one which should provide a critical test of the relevance of a research program that interprets the bulk of aggregate fluctuations as resulting from those shocks. Conditional on my identification scheme being correct, the empirical framework developed above allows me to address that question in a straightforward way, by examining the decomposition of output and employment time series into technology vs. demand-driven components.

The basic output of that exercise is displayed in Figures 6.a and 6.b.. In order to save space, I report only results for the U.S., based on the bivariate VAR using hours data. ${ }^{26}$ The figures display the two estimated components of output and hours, detrended using the HP filter $(\lambda=1600)$. In addition, the two figures show as a shaded area the periods corresponding to the nine NBER-dated recessions. The patterns that emerge seem quite revealing in a number of ways.

Consider the output and employment fluctuations that the empirical model identifies as being driven by technology shocks-and which are shown in Figure 6.a . Though such fluctuations are by no means negligible, the patterns displayed by the two series hardly coincide with "recognizable" US business cycles. That is particularly true in one dimension: the strong, positive comovement of GDP and employment that is generally viewed as central characteristic of business cycles seems hardly present in Figure 6.a.; in fact the estimated correlation between the two series is -0.02 .

A look at the estimated demand components of the GDP and hours series-

\footnotetext{
${ }^{26}$ Results for most other specifications and countries are qualitatively similar.
} 
shown in Figure 6.b.- yields a completely different picture. In addition to the dominant contribution of demand shocks to US fluctuations-which a comparison of Fig. 6.a. and Fig. 6.b. makes apparent-the estimates point to an unambiguous pattern of positive comovements of employment and output over the cycle, with an estimated correlation of 0.97 .

\section{Concluding Comments}

Many macroeconomists seem to have been attracted by the hypothesis that aggregate fluctuations experienced by industrialized countries can be explained, at least to a first approximation, as the result of the economy's response to exogenous, random variations in technology. That approach is often justified by the (largely recognized) ability of RBC models to generate time series for a number of aggregates whose unconditional moments display patterns similar to their empirical counterparts.

In the present paper I have tried to provide some evidence that raises some doubts on the empirical merits of that class of models. The paper builds on the observation of a near-zero unconditional correlation between productivity and employment, both in the US and in other industrialized economies. Proponents of RBC models have interpreted that evidence as reflecting the coexistence of technology shocks with other shocks; under that view, the positive employment-productivity correlation induced by the former (resulting from labor demand shifts) is roughly offset by the negative correlation resulting from non-technology shocks (and which will be manifested in labor supply shifts). Yet, and to the extent that technology shocks are a significant source of fluctuations in those variables, we would expect $\mathrm{RBC}$ models to provide at least an accurate description of the economy's response to such shocks. For the majority of the G7 countries, however, the estimates of the effects of technology shocks yield a picture which is hard to reconcile with the predictions of those models: positive technology shocks lead to a decline in employment, and tend to generate a negative comovement between that variable and productivity.

The observed results seems to favor instead a class of models with imperfect competition, sticky prices, and variable effort. In those models-a stylized version of which has been presented in Section 2-the combination of price rigidities and demand constraints leads firms to contract employment in the face of an exogenous increase in multifactor productivity, whereas the 
presence of variable effort explains why measured labor productivity may rise with employment in response to an demand expansion. Needless to say, the nature of aggregate fluctuations and the potential role for policy associated with such an economy are very different from those identified with the RBC paradigm. 


\section{REFERENCES}

Aiyagari, Rao, Lawrence Christiano, and Martin Eichenbaum (1992): "The Output, Employment, and Interest Rate Effects of Government Consumption, " Journal of Monetary Economics 30, 73-86.

Basu, Susanto (1995): "Procyclical Productivity: Increasing Returns or Cyclical Utilization?," NBER WP\#5336.

Benassy, Jean-Pascal (1995): "Money and Wage Contracts in an Optimizing Model of the Business Cycle," Journal of Monetary Economics 35, no.2, 303-316.

Blanchard, Olivier J. (1989): "A Traditional Interpretation of Macroeconomic Fluctuations," American Economic Review, vol. 79, no. 5, 1146-1164.

Blanchard, Olivier J., and Danny Quah (1989): "The Dynamic Effects of Aggregate Demand and Supply Disturbances," American Economic Review 79 , no. 4, 654-673.

Blanchard, Olivier J., Robert Solow, and B.A. Wilson (1995): "Productivity and Unemployment," mimeo.

Burnside, Craig, Martin Eichenbaum, and Sergio Rebelo (1993): "Labor Hoarding and the Business Cycle, " Journal of Political Economy 101, no. 2, 245-273.

Christiano, Lawrence J. and Martin Eichenbaum (1992): "Current Real Business Cycle Theories and Aggregate Labor Market Fluctuations," American Economic Review 82, 430-450.

Cooley, Thomas F. and Jang-Ok Cho (1990): "The Business Cycle with Nominal Contracts,", mimeo.

Cooley, Thomas F., and Mark Dwyer (1995): "Business Cycle Analysis Without Much Theory: A Look At Structural VARs," mimeo

Forni, Mario, and Lucrezia Reichlin (1995): "Let's Get Real: A Dynamic Factor Analytical Approach to Disaggregated Business Cycles," CEPR Discussion Paper Series \#1244.

Galí, Jordi (1994): "Government Size and Macroeconomic Stability," European Economic Review, vol. 38, 117-132.

Galí, Jordi (1996): "Fluctuaciones y Persistencia del Empleo en España," in R. Marimon ed., La Economía Española: una Visión Diferente, CREI and Antoni Bosch, editor, Barcelona, 1996, 139-169. 
Gamber, Edward N., and Frederick L. Joutz (1993): "The Dynamic Effects of Aggregate Demand and Supply Disturbances: Comment," American Economic Review, vol. 83, no. 5, 1387-1393.

Gordon, Robert J. (1990): "Are Procyclical Productivity Fluctuations a Figment of Measurement Error ?," mimeo.

Hairault, Jean-Olivier, and Franck Portier (1993): "Money, New Keynesian Macroeconomics, and the Business Cycle," European Economic Review 37, 33-68.

Hairault, Jean-Olivier, François Langot, and Franck Portier (1995): "Time to Implement and Aggregate Fluctuations," mimeo.

Hansen, Gary D., and Randall Wright (1992): "The Labor Market in Real Business Cycle Theory," Quarterly Review, Federal Reserve Bank of Minneapolis, 2-12.

Kim, Jinill (1996): "Monetary Policy in a Stochastic Equilibrium Model with Real and Nominal Rigidities," mimeo.

King, Robert G., Charles I. Plosser, and Sergio T. Rebelo (1988): "Production, Growth, and Business Cycles. I. The Basic Neoclassical Model" Journal of Monetary Economics 21, 195-232.

King, Robert G., and Mark Watson (1995): "Money, Prices, Interest Rates, and the Business Cycle," Review of Economics and Statistics, vol. 58, no $1,35-53$.

Kydland, Finn E. and Edward C. Prescott (1991): "Time to Build and Aggregate Fluctuations," Econometrica 50, 1345-1370.

Kydland, Finn E. and Edward C. Prescott (1996): "The Computational Experiment: An Econometric Tool," Journal of Economic Perspectives, vol. 10, no. $1,69-85$.

Mishkin, Frederic S. (1992): "Is the Fisher effect for real ?," Journal of Monetary Economics 30, 195-215.

Prescott, Edward C. (1986): "Theory Ahead of Business Cycle Measurement," F.R.B. of Minneapolis Quarterly Review 10, 9-22.

Rotemberg, Julio J. (1995): "Prices, Output, and Hours: An Empirical Analysis Based on a Sticky Price Model," Journal of Monetary Economics, forthcoming.

Rotemberg, Julio J. and Michael Woodford (1996): "Real Business Cycle Models and the Forecastable Movements in Output, Hours, and Consumption," American Economic Review, vol. 86, no. 1, 71-89.

Sbordone, Argia M. (1995): "Cyclical Productivity in a Model of Labor Hoarding," Princeton University, mimeo. 
Shapiro, Matthew D., and Mark Watson (1988): "Sources of Business Cycle Fluctuations," in Stanley Fischer ed., NBER Macroeconomics Annual 1988, 111-148.

Singleton, Kenneth J., (1990): "Specification and Estimation of Intertemporal Asset Pricing Models," in Friedman and Hahn eds., Handbook of Monetary Economics, vol. 1, 583-626.

Sims, Christopher A. (1989): "Models and Their Uses," American Journal of Agricultural Economics 71, no. 2, 489-494.

Sims, Christopher A. (1996): "Macroeconomics and Methodology," Journal of Economic Perspectives, vol. 10, no. 1, 105-120.

Watson, Mark W. (1993): "Measures of Fit for Calibrated Models," Journal of Political Economy, vol. 101, no. 6, 1011-1041. 
Table 1: Unit Root Tests

\begin{tabular}{l|cc}
\multicolumn{3}{c}{ U.S. Data } \\
\hline \hline \multicolumn{1}{c}{ (a) } & level & $\Delta$ \\
\hline$n_{h}$ & -3.34 & $-7.36^{*}$ \\
$n_{e}$ & -2.60 & $-6.50^{*}$ \\
$x_{h}$ & -3.26 & $-6.79^{*}$ \\
$x_{e}$ & -3.20 & $-5.67^{*}$ \\
$y$ & -2.84 & $-6.04^{*}$ \\
\hline \multicolumn{1}{c}{$(b)$} & level & $\Delta$ \\
\hline$m$ & 0.90 & -2.76 \\
$p$ & 1.30 & -3.27 \\
$m-p$ & -2.12 & $-3.77^{*}$ \\
$i$ & -2.36 & $-4.66^{*}$ \\
$i-\Delta p$ & $-3.76^{*}$ & $-7.47^{*}$ \\
\hline \hline
\end{tabular}

Note: t-statistic for the null hypothesis of a unit root in the level or the first difference of each time series, based on an ADF test with 4 lags, intercept and time trend. 5\% significance critical value: -3.41 (lower values denoted with asterisk). Sample period: 49:1-94:4, with the exception of $m$ and $m-p$ (59:1-94:4). Source: Citibase. 
Table 2: Employment-Productivity Correlations U.S. Data

\begin{tabular}{l|c||cc||cc}
\hline & Data & \multicolumn{2}{c||}{ Bivariate } & \multicolumn{2}{c}{ Large VAR } \\
\hline \multicolumn{1}{c||}{$(\mathrm{a})$} & $\hat{\rho}$ & $\widehat{\rho}_{z}$ & $\widehat{\rho}_{m}$ & $\widehat{\rho}_{z}$ & $\widehat{\rho}_{m}$ \\
\hline hours: & & & & & \\
$\left(\Delta n_{h}, \Delta x_{h}\right)$ & -0.26 & -0.83 & 0.28 & -0.68 & 0.25 \\
$\left(\widehat{n}_{h}, \widehat{x}_{h}\right)$ & -0.29 & -0.79 & 0.04 & -0.68 & 0.16 \\
\hline \multicolumn{1}{c||}{$(\mathrm{b})$} & $\widehat{\rho}$ & $\widehat{\rho}_{z}$ & $\widehat{\rho}_{m}$ & $\widehat{\rho}_{z}$ & $\widehat{\rho}_{m}$ \\
\hline employment: & & & & & \\
$\left(\Delta n_{e}, \Delta x_{e}\right)$ & -0.02 & -0.85 & 0.65 & -0.64 & 0.42 \\
$\left(\widehat{n}_{e}, \widehat{x}_{e}\right)$ & 0.28 & -0.68 & 0.54 & -0.62 & 0.54 \\
\hline \hline
\end{tabular}

Note: $\widehat{\rho}$ is the estimated unconditional correlation of employment and productivity, $\hat{\rho}_{z}$ is the estimated correlation of the technology components of the same variables, $\widehat{\rho}_{m}$ is the estimated correlation of their non-technology (demand) component. Panel (a) reports results obtained using hours as labor input series, whereas Panel (b) reports the results for employment. The transformation of the raw data or the estimated components on which correlations are computed is represented by $\Delta$ (first-differences) and $\sim$ (HP-detrended). See text for a description of the model specification and data sources. 
Table 3: Unit Root Tests International Data

\begin{tabular}{l|cccccc}
\hline \hline \multicolumn{1}{l}{} & $n$ & $x$ & $y$ & $\Delta n$ & $\Delta x$ & $\Delta y$ \\
\hline Canada & -1.75 & -1.22 & -1.67 & $-4.26^{*}$ & $-4.49^{*}$ & $-4.67^{*}$ \\
U.K. & -3.16 & -2.39 & -2.39 & -3.32 & $-4.90^{*}$ & $-4.40^{*}$ \\
Germany & -1.74 & -3.30 & -3.33 & -3.32 & $-4.86^{*}$ & $-4.40^{*}$ \\
France & $-3.48^{*}$ & -2.66 & -3.07 & $-3.83^{*}$ & $-4.41^{*}$ & $-3.93^{*}$ \\
Italy & 0.04 & -1.15 & -2.63 & -3.25 & $-4.64^{*}$ & $-5.28^{*}$ \\
Japan & -2.69 & -0.00 & -2.17 & $-3.78^{*}$ & $-3.98^{*}$ & $-3.90^{*}$ \\
\hline \hline
\end{tabular}

Note: t-statistic for the null hypothesis of a unit root in the level or the first difference of each time series, based on an ADF test with 4 lags, intercept and time trend. 5\% significance critical value: -3.41 (lower values denoted with asterisk). Sample period: Canada (62:194:4), U.K. (62:1-94:3), Germany (70:1-94:4), France (70:1-94:4), Italy (70:1-94:3), and Japan (62:1-94:4). Data source: OECD Quarterly National Accounts. 
Table 4: Employment-Productivity Correlations: International Data

\begin{tabular}{|c|c|c|c|c|c|c|c|c|c|}
\hline \multirow{4}{*}{$\begin{array}{c}(\Delta n, \Delta x) \\
(\widehat{n}, \widehat{x})\end{array}$} & \multicolumn{3}{|c|}{ Canada } & \multicolumn{3}{|c|}{ U.K. } & \multicolumn{3}{|c|}{ Germany } \\
\hline & $\widehat{\rho}$ & $\widehat{\rho_{z}}$ & $\widehat{\rho}_{m}$ & $\hat{\rho}$ & $\widehat{\rho}_{z}$ & $\widehat{\rho}_{m}$ & $\widehat{\rho}$ & $\widehat{\rho}_{z}$ & $\widehat{\rho}_{m}$ \\
\hline & -0.12 & -0.59 & 0.59 & -0.10 & -0.90 & 0.44 & 0.08 & -0.63 & 0.22 \\
\hline & -0.09 & 0.08 & 0.56 & -0.10 & -0.92 & 0.23 & 0.07 & -0.80 & 0.14 \\
\hline \multirow{4}{*}{$\begin{array}{c}(\Delta n, \Delta x) \\
(\widehat{n}, \widehat{x})\end{array}$} & \multicolumn{3}{|c|}{ France } & \multicolumn{3}{|c|}{ Italy } & \multicolumn{3}{|c|}{ Japan } \\
\hline & $\widehat{\rho}$ & $\hat{\rho}_{z}$ & $\widehat{\rho}_{m}$ & $\widehat{\rho}$ & $\widehat{\rho}_{z}$ & $\widehat{\widehat{\rho}}_{m}$ & $\bar{\rho}$ & $\overline{\bar{\rho}}_{z}$ & $\widehat{\rho}_{z}$ \\
\hline & -0.18 & -0.75 & 0.62 & -0.47 & -0.93 & 0.30 & -0.07 & 0.44 & -0.60 \\
\hline & 0.29 & -0.81 & 0.83 & -0.25 & -0.91 & 0.43 & 0.21 & 0.47 & 0.11 \\
\hline
\end{tabular}

Note: $\widehat{\rho}$ is the estimated unconditional correlation of employment and productivity, $\hat{\rho}_{z}$ is the estimated correlation of the technology components of the same variables, $\hat{\rho}_{m}$ is the estimated correlation of their non-technology (demand) component. Panel (a) reports results obtained using hours as labor input series, whereas Panel (b) reports the results for employment. The transformation of the raw data or the estimated components on which correlations are computed is represented by $\Delta$ (first-differences) and ${ }^{\wedge}$ (HP-detrended). See text for a description of the model specification and data sources. 
Table 5: SRIRL Estimates

\begin{tabular}{c|c||c||c}
\multicolumn{4}{c}{ U.S. Data } \\
\hline \hline & OLS & Bivariate & Large VAR \\
\hline hours: & & & \\
$\widehat{\varphi}$ & 0.79 & 1.16 & 1.30 \\
s.e. & $(0.05)$ & $(0.05)$ & $(0.11)$ \\
\hline employment: & & & \\
$\widehat{\varphi}$ & 0.97 & 1.46 & 1.50 \\
s.e. & $(0.11)$ & $(0.10)$ & $(0.14)$ \\
\hline \hline
\end{tabular}

Note: $\hat{\varphi}$ is the OLS estimate of $\varphi$ in the regression equation $\Delta y_{t}=$ $\delta+\varphi \Delta n_{t}^{*}+u_{t}$, where $\Delta n_{t}^{*}=\Delta n_{t}$ (i.e., observed employment or hours growth) in "OLS", and $\Delta n_{t}^{*}=\Delta n_{t}^{m}$ (i.e., the estimated demand component of employment or hours growth) in "Bivariate" and "Large VAR". 
Table 6: SRIRL Estimates

International Data

\begin{tabular}{c|cc||cc||cc}
\hline \hline & \multicolumn{2}{|c||}{ Canada } & \multicolumn{2}{c||}{ U.K. } & \multicolumn{2}{c||}{ Germany } \\
\hline & OLS & Bivariate & OLS & Bivariate & OLS & Bivariate \\
\cline { 2 - 7 }$\varphi$ & 0.84 & 1.19 & 0.78 & 1.72 & 1.15 & 1.34 \\
s.e. & $(0.11)$ & $(0.10)$ & $(0.24)$ & $(0.25)$ & $(0.18)$ & $(0.17)$ \\
\hline \hline & \multicolumn{2}{|c||}{ France } & \multicolumn{2}{c||}{ Italy } & \multicolumn{2}{c|}{ Japan } \\
\hline & OLS & Bivariate & OLS & Bivariate & OLS & Bivariate \\
\cline { 2 - 7 }$\hat{\varphi}$ & 1.00 & 1.59 & 0.33 & 1.25 & 0.79 & 0.50 \\
s.e. & $(0.17)$ & $(0.18)$ & $(0.14)$ & $(0.15)$ & $(0.23)$ & $(0.28)$ \\
\hline \hline
\end{tabular}

Note: $\hat{\varphi}$ is the OLS estimate of $\varphi$ in the regression equation $\Delta y_{t}=$ $\delta+\varphi \Delta n_{t}^{*}+u_{t}$, where $\Delta n_{t}^{*}=\Delta n_{t}$ (i.e., observed employment or hours growth) in "OLS", and $\Delta n_{t}^{*}=\Delta n_{t}^{m}$ (i.e., the estimated demand component of employment or hours growth) in "Bivariate". 

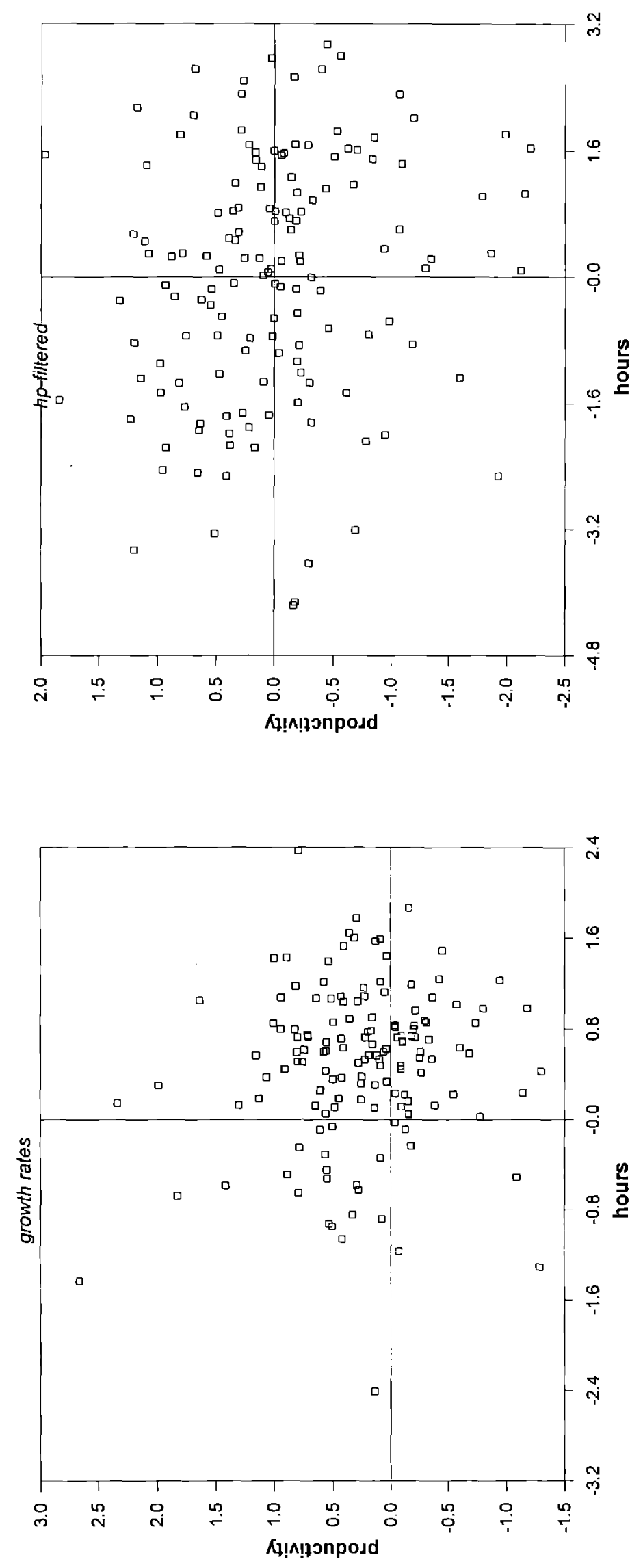

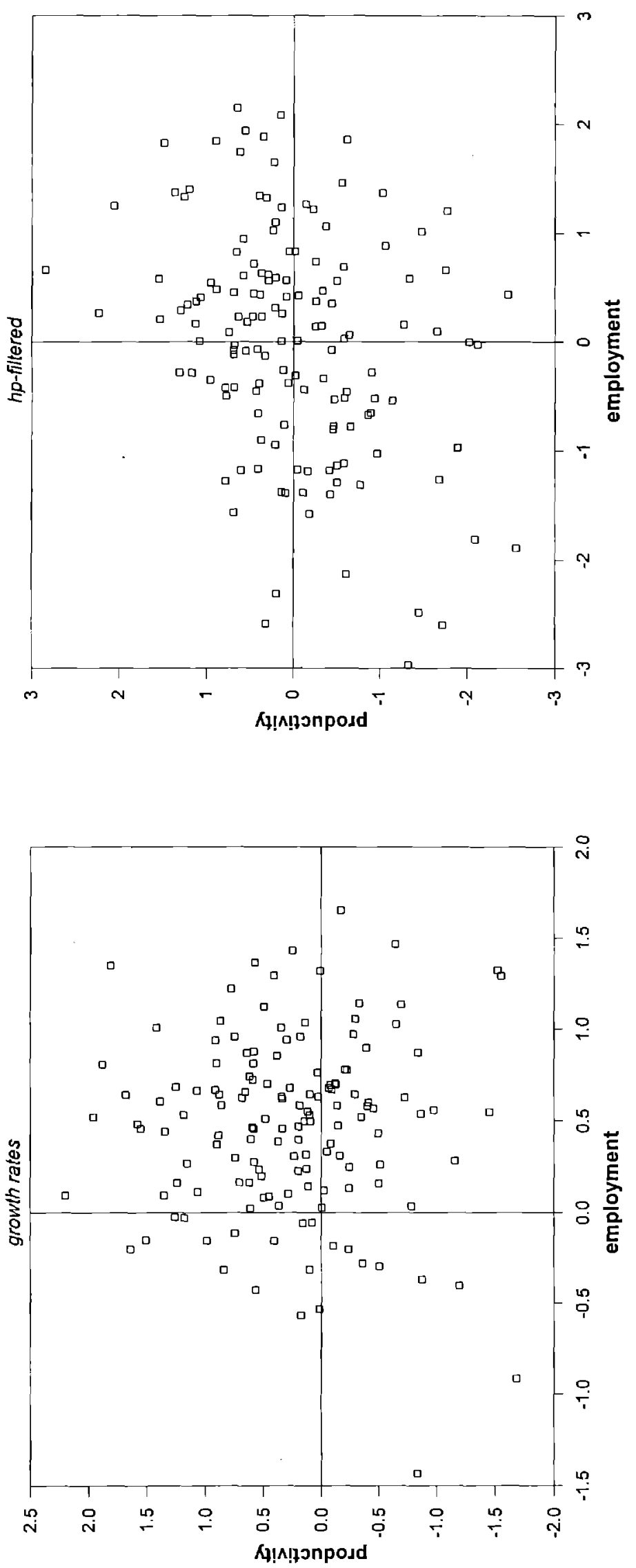

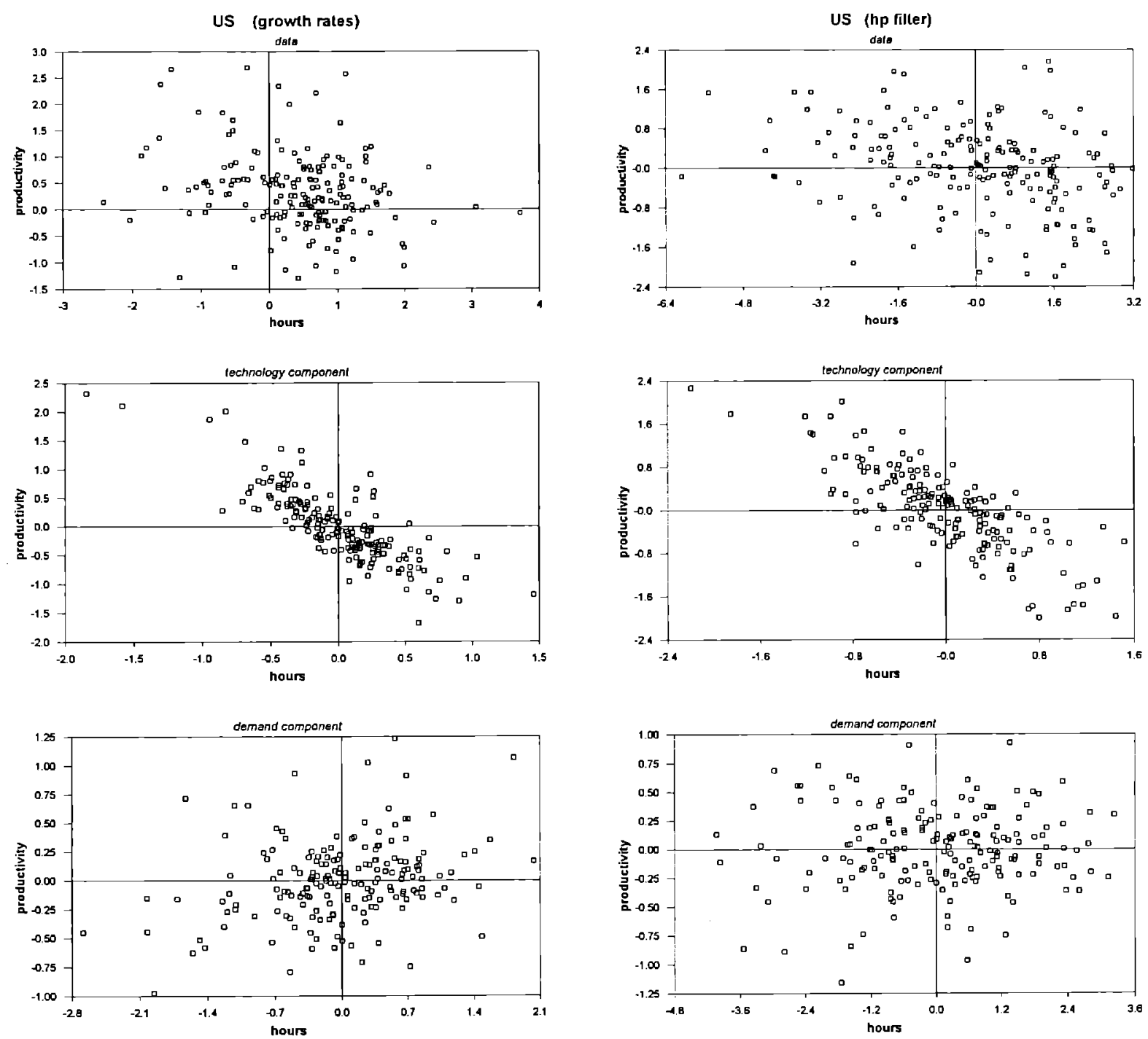

Figure 2 .a. 
US (growth rales)

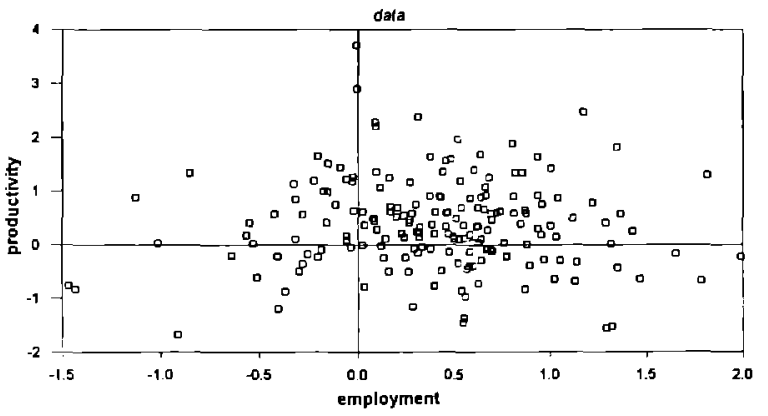

lechnology componex
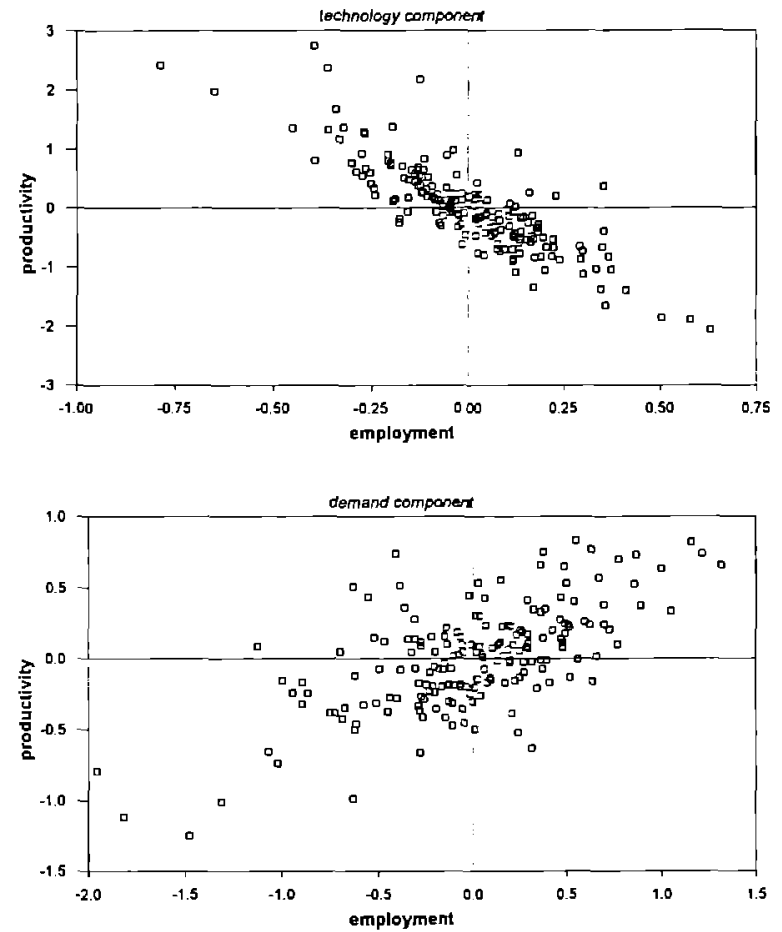

US (hp filter)

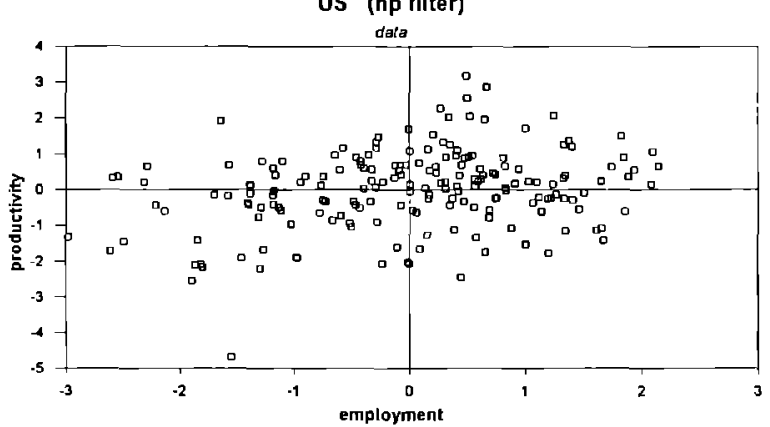

technology companent
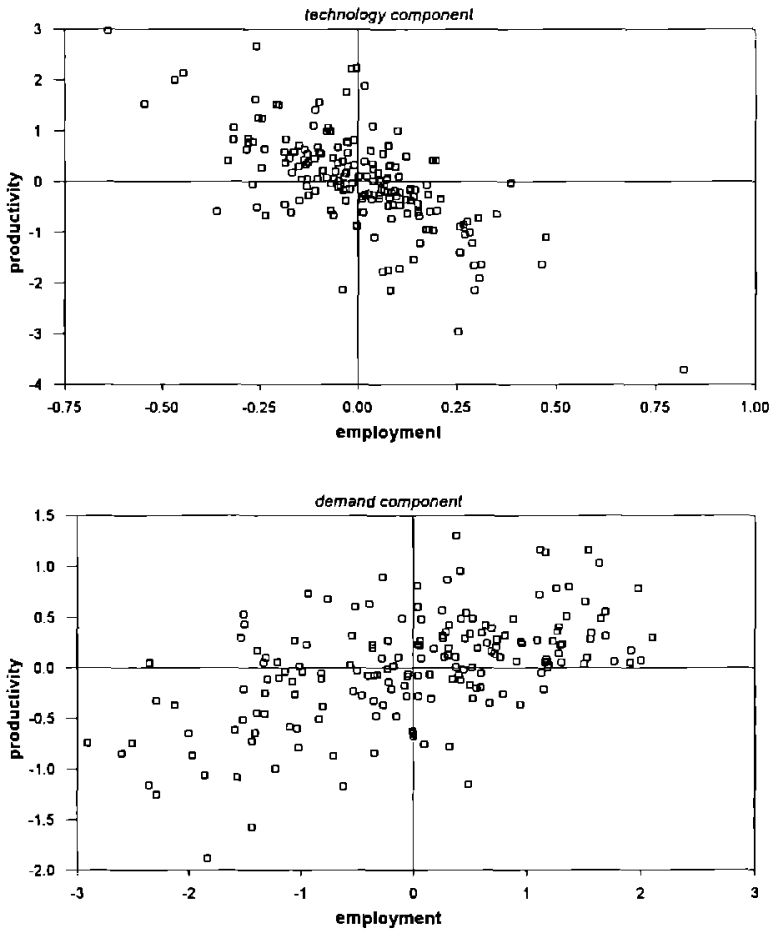

Figure 2.b. 
US: technology shock
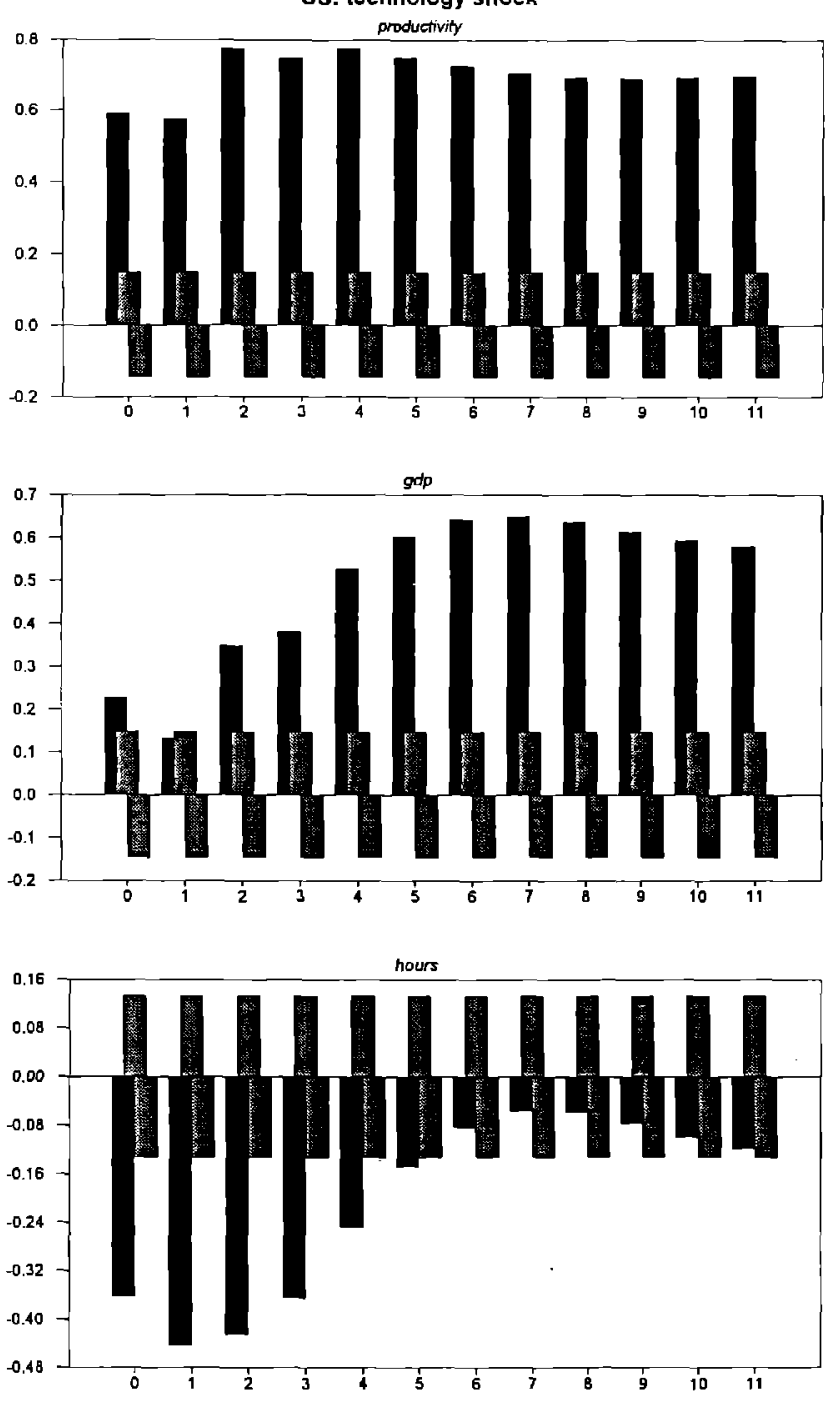

US: demand shock
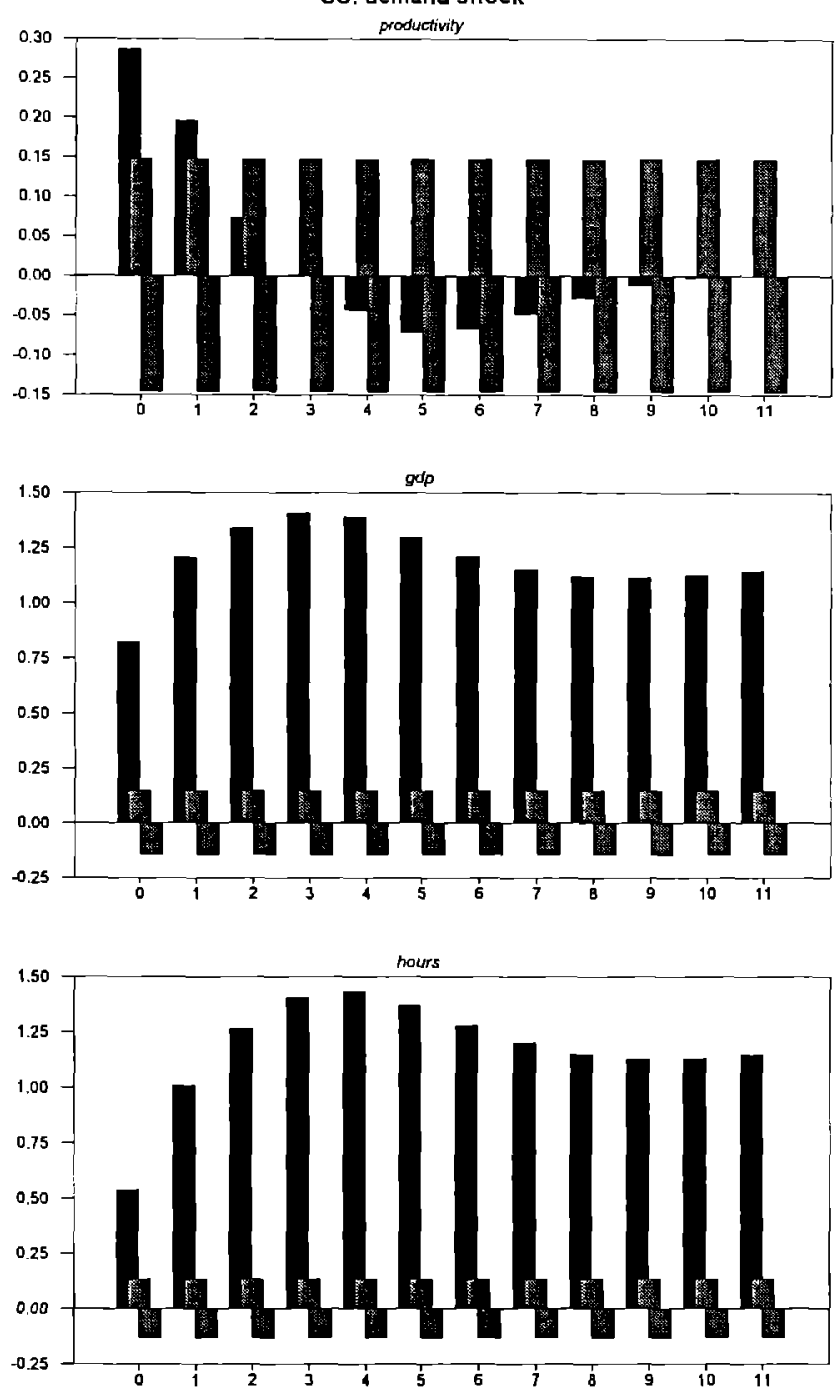

Figure 3.a. 
US: technology shock
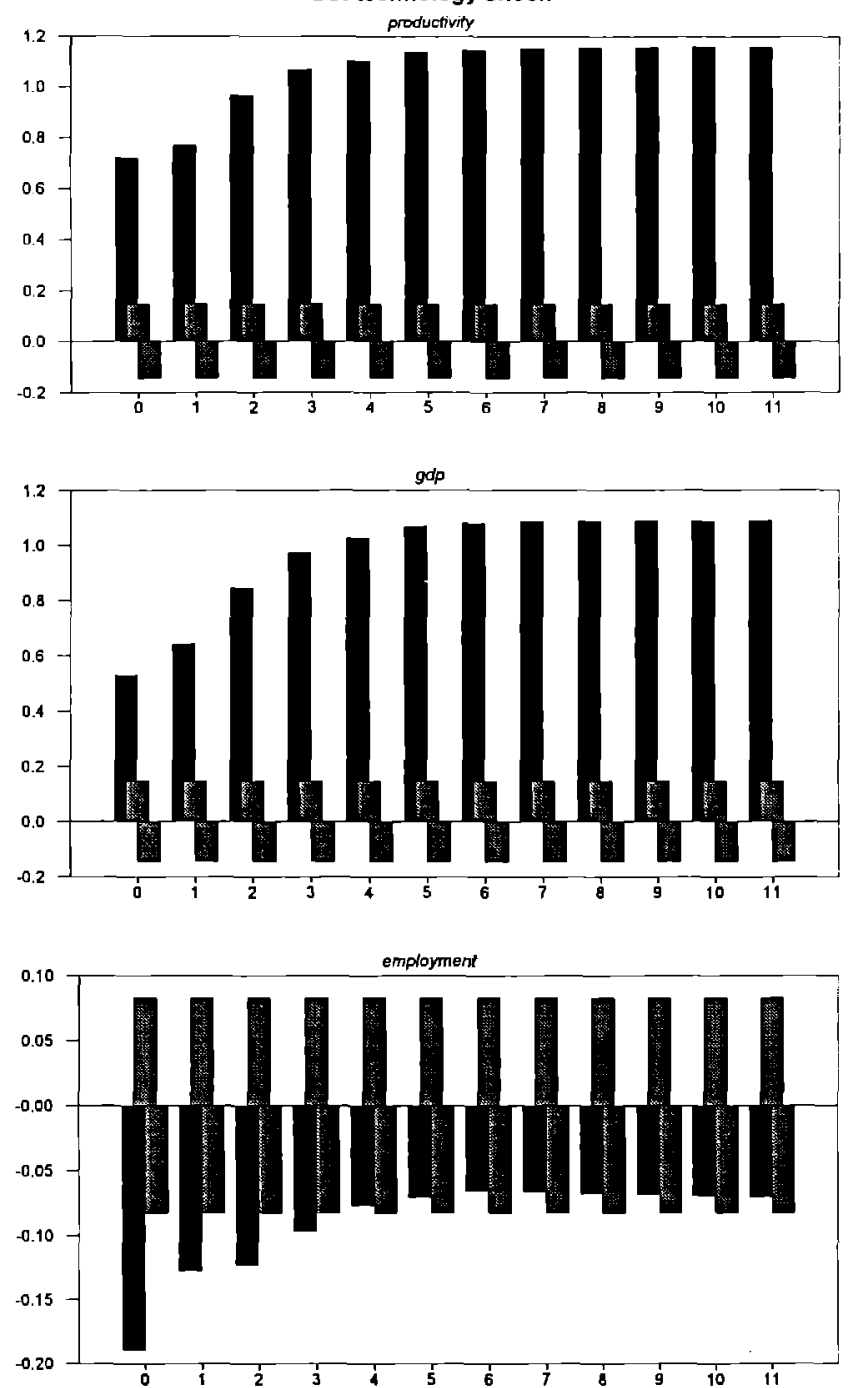

US: demand shock

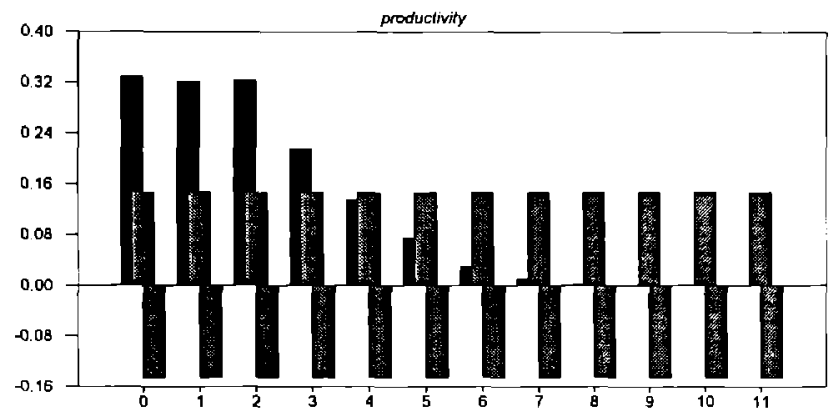

gdp
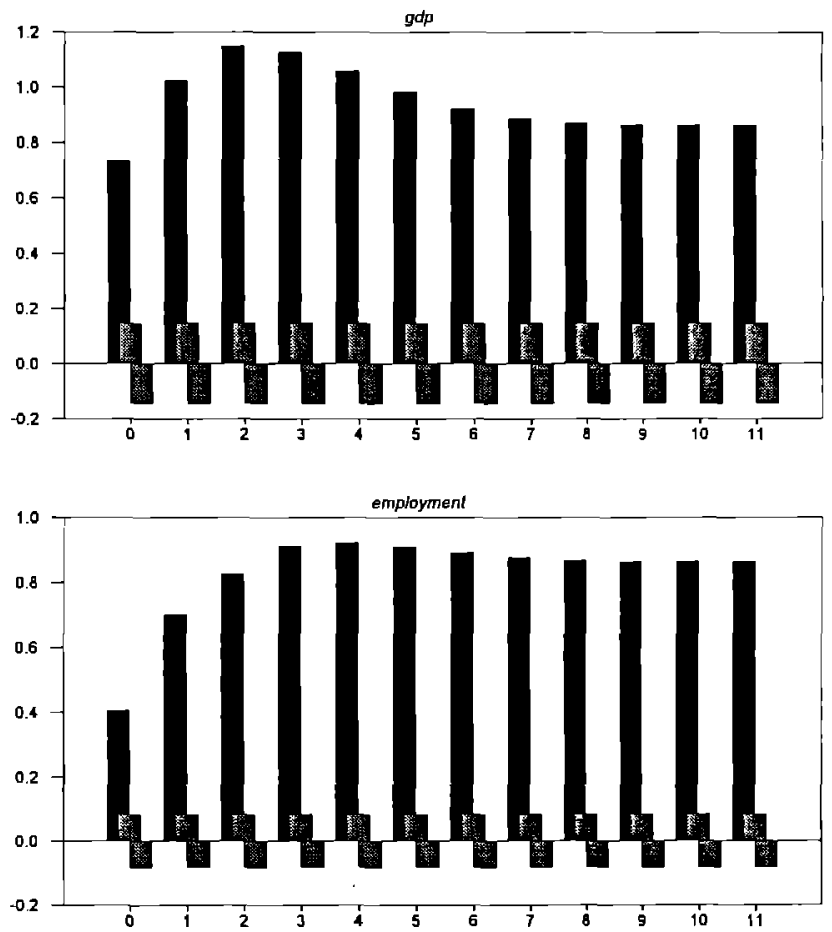

Figure 3.b. 

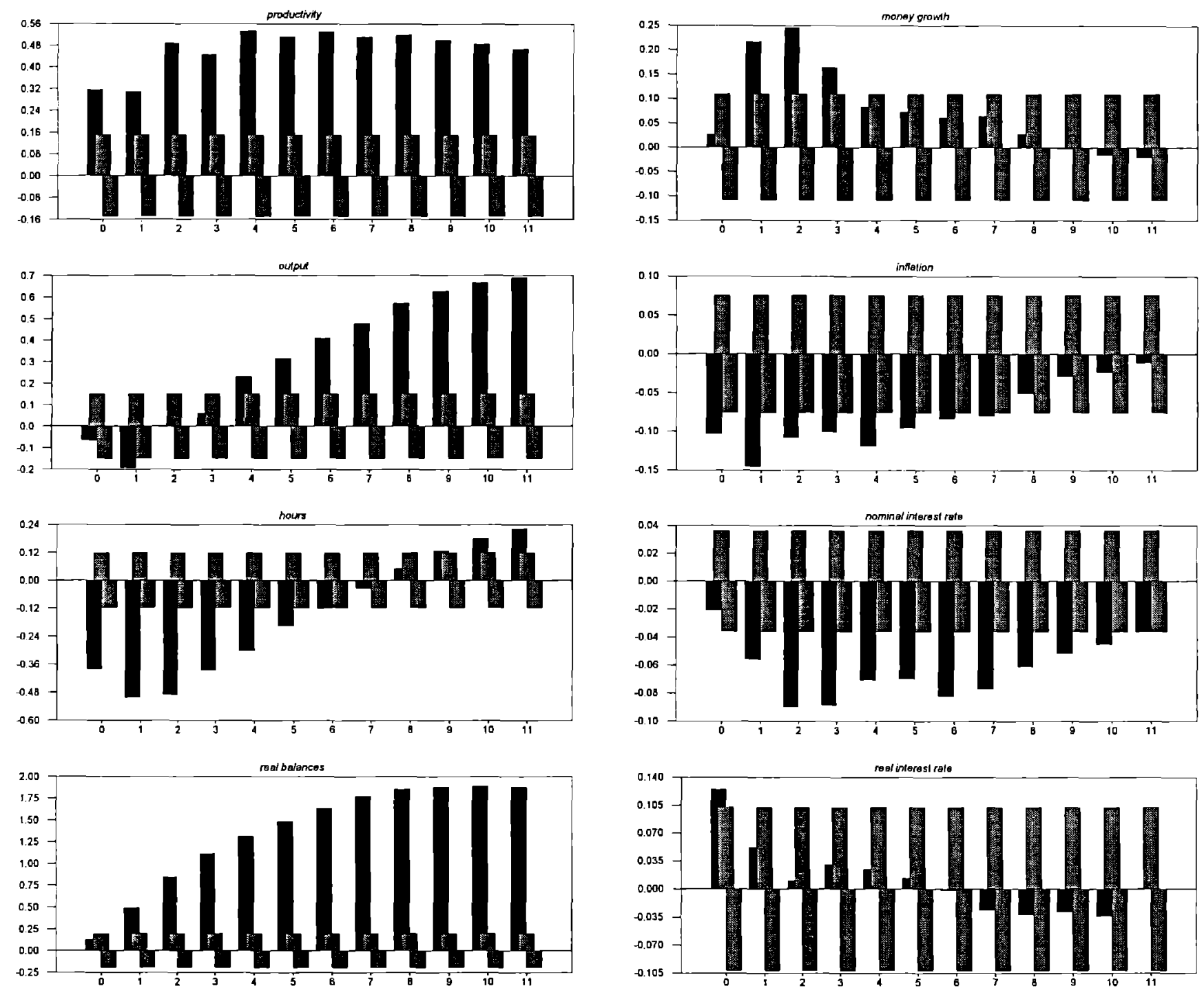

Figure 4.a. 

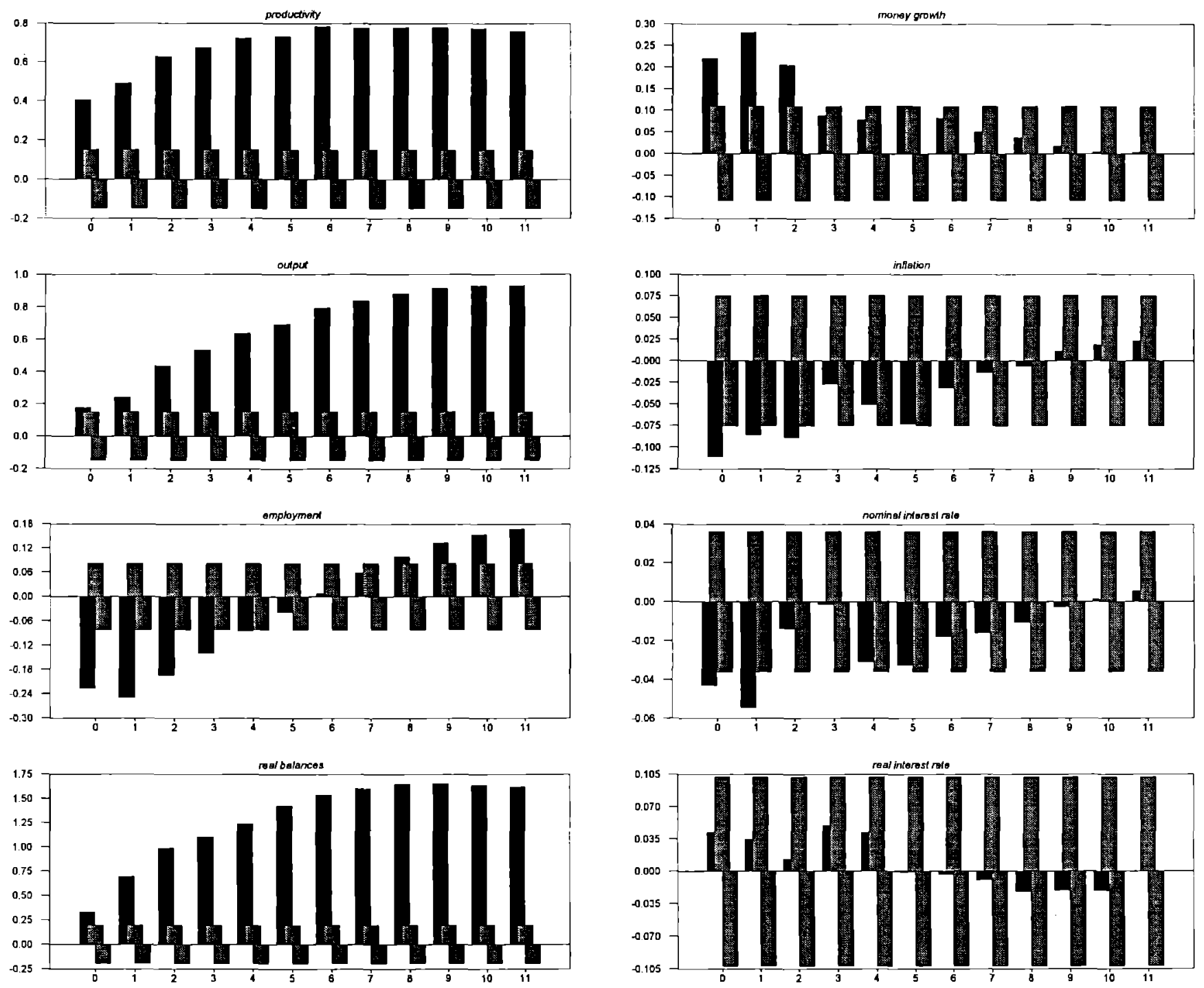

Figure 4.b. 

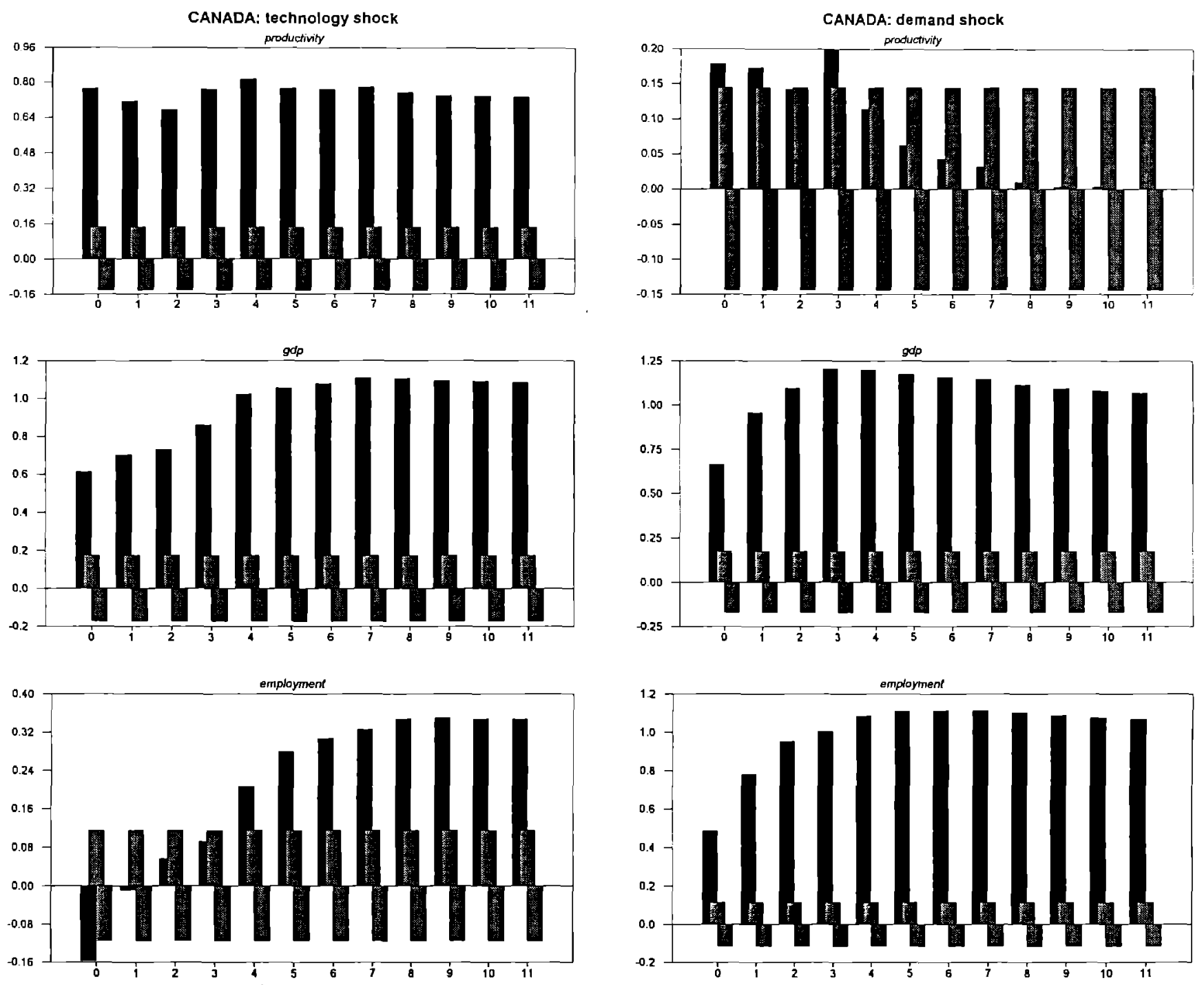

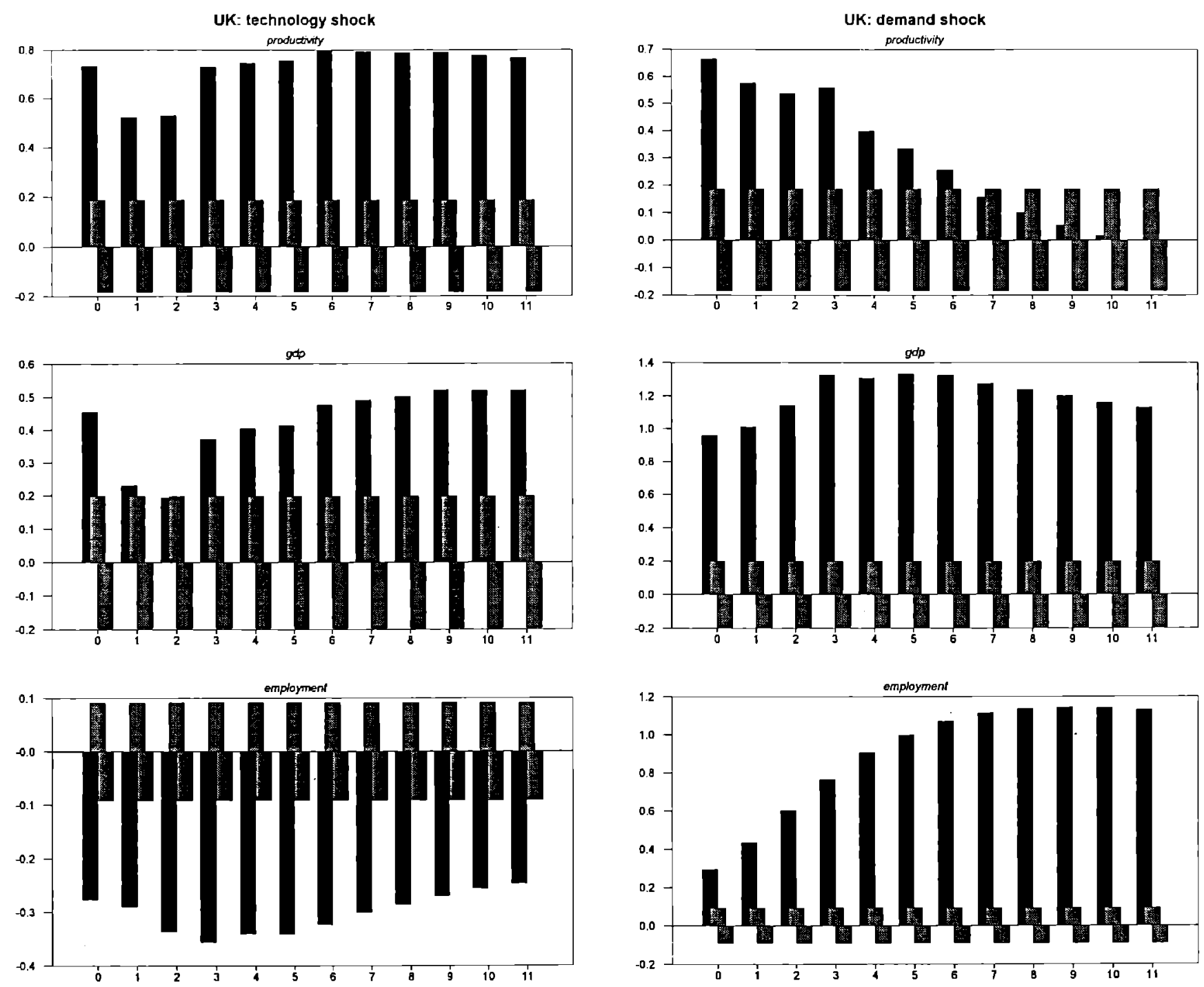

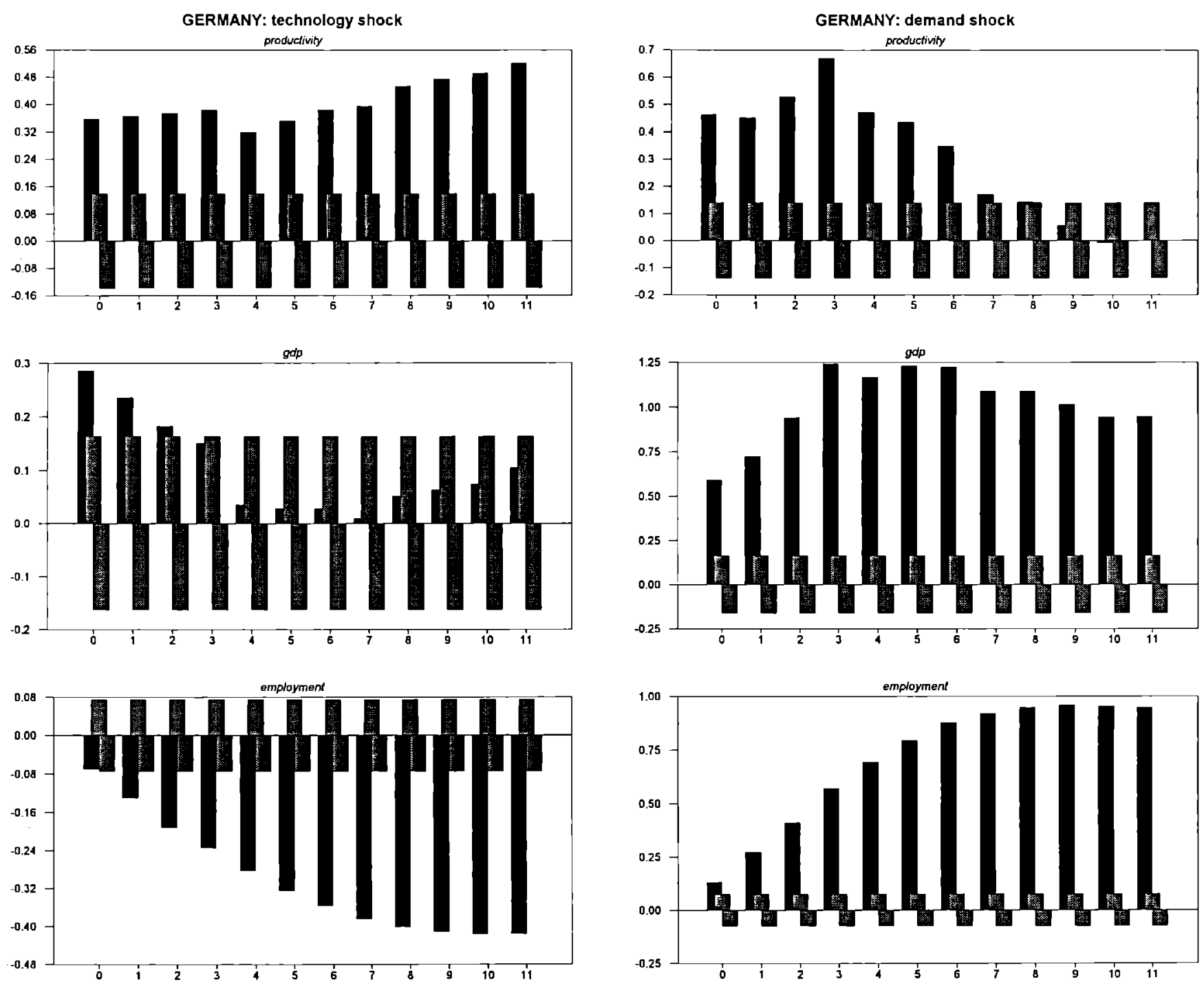

Figure 5.c. 
FRANCE: technology shock
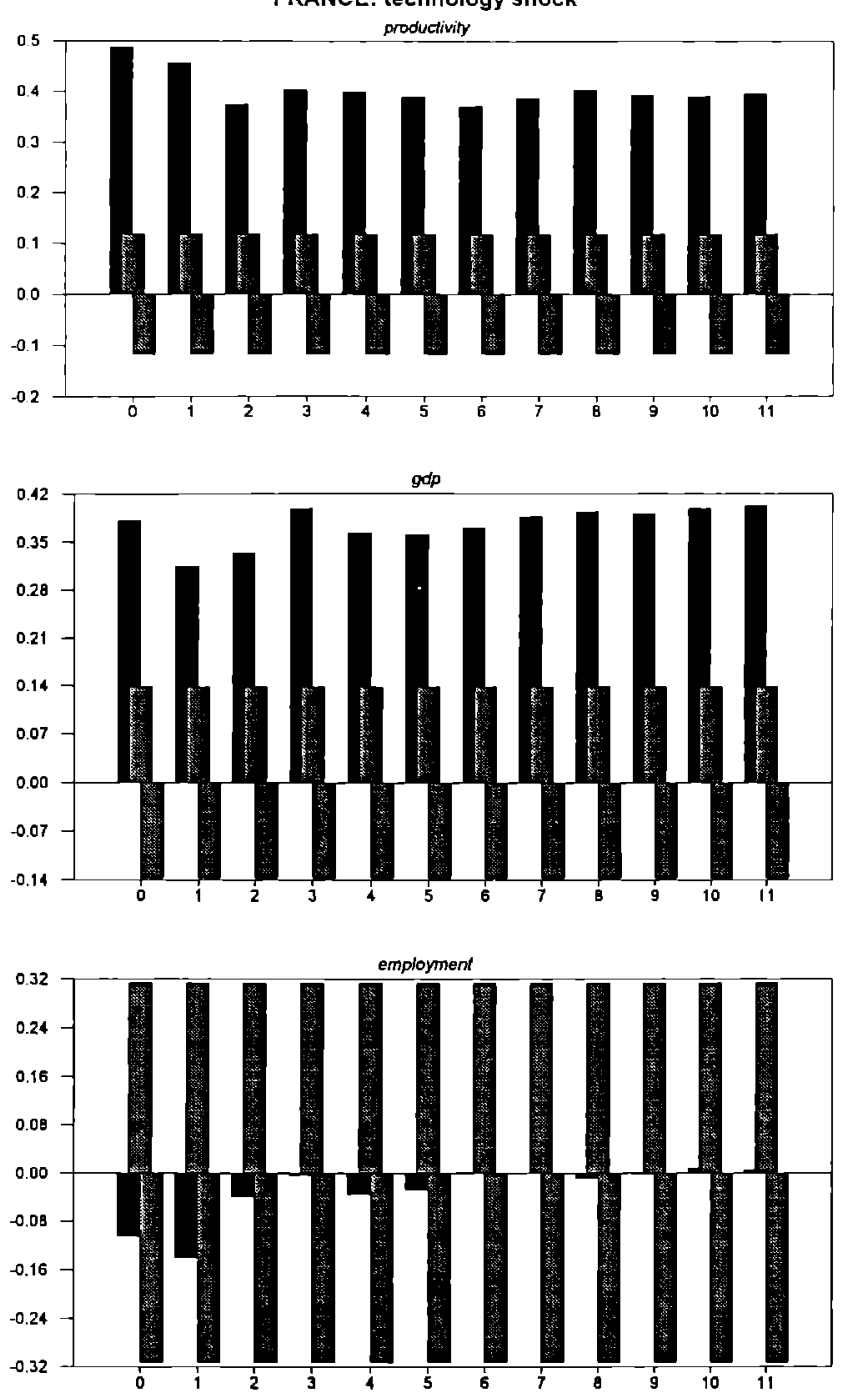

FRANCE: demand shock
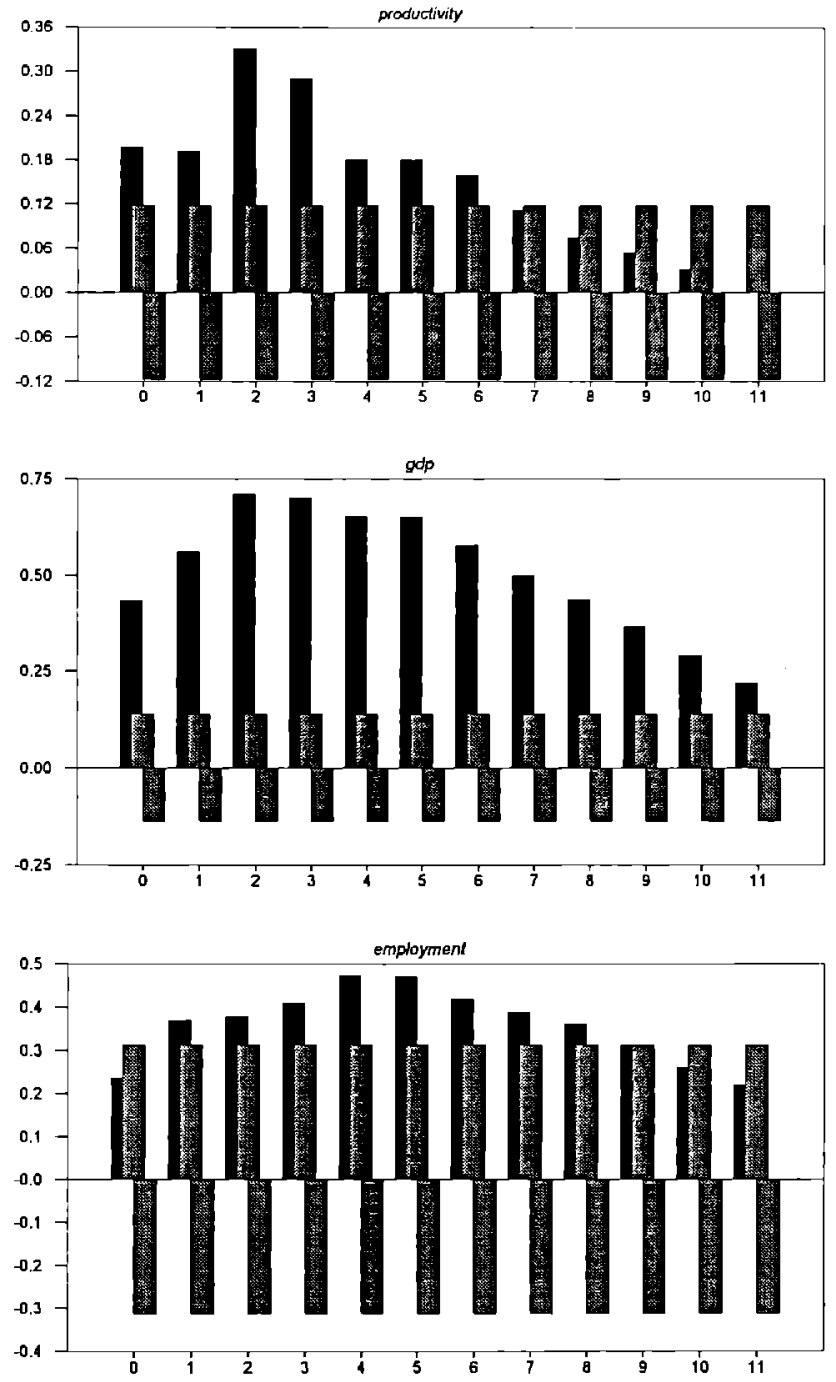

Figure 5.d. 

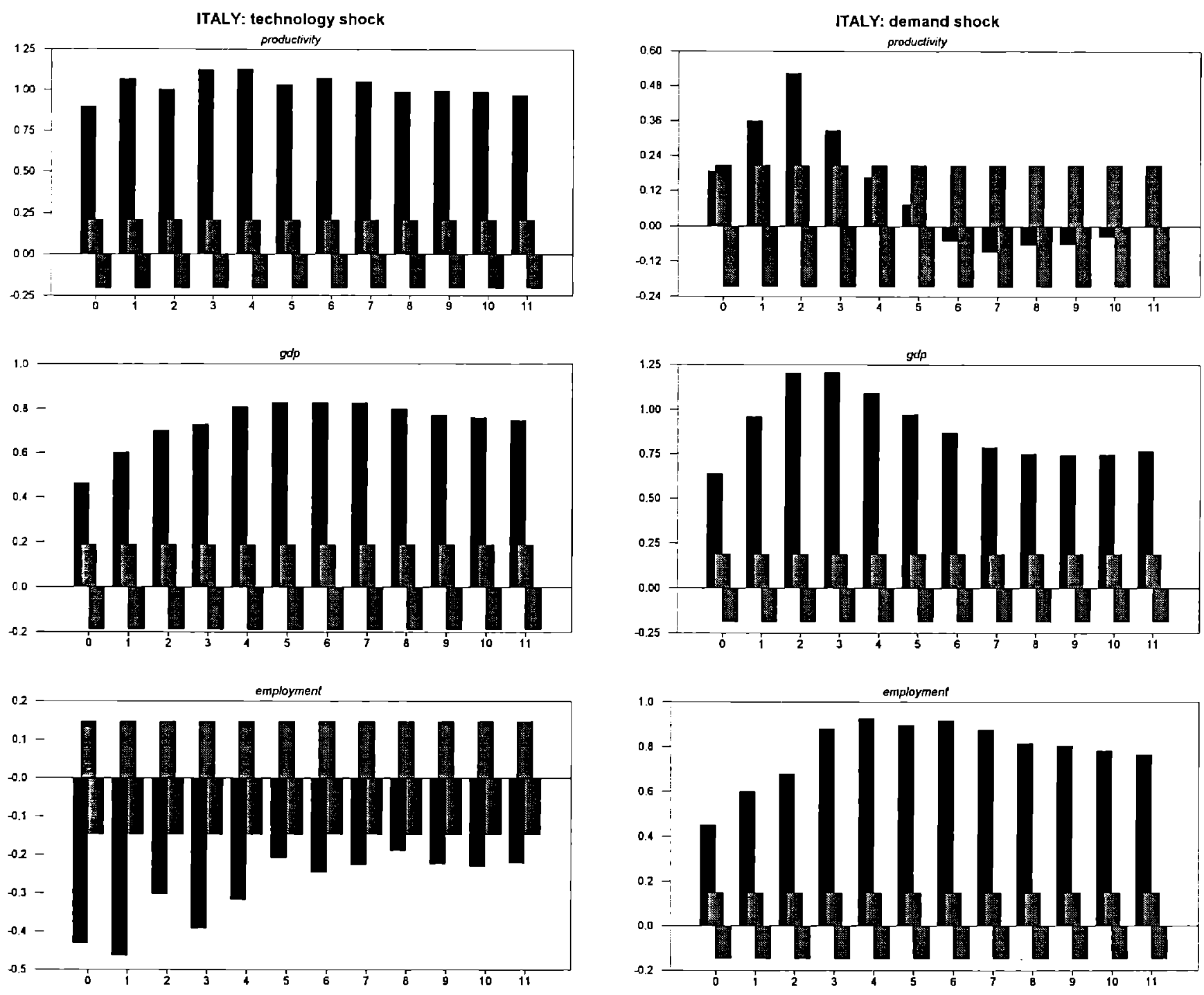

Figure 5.e. 

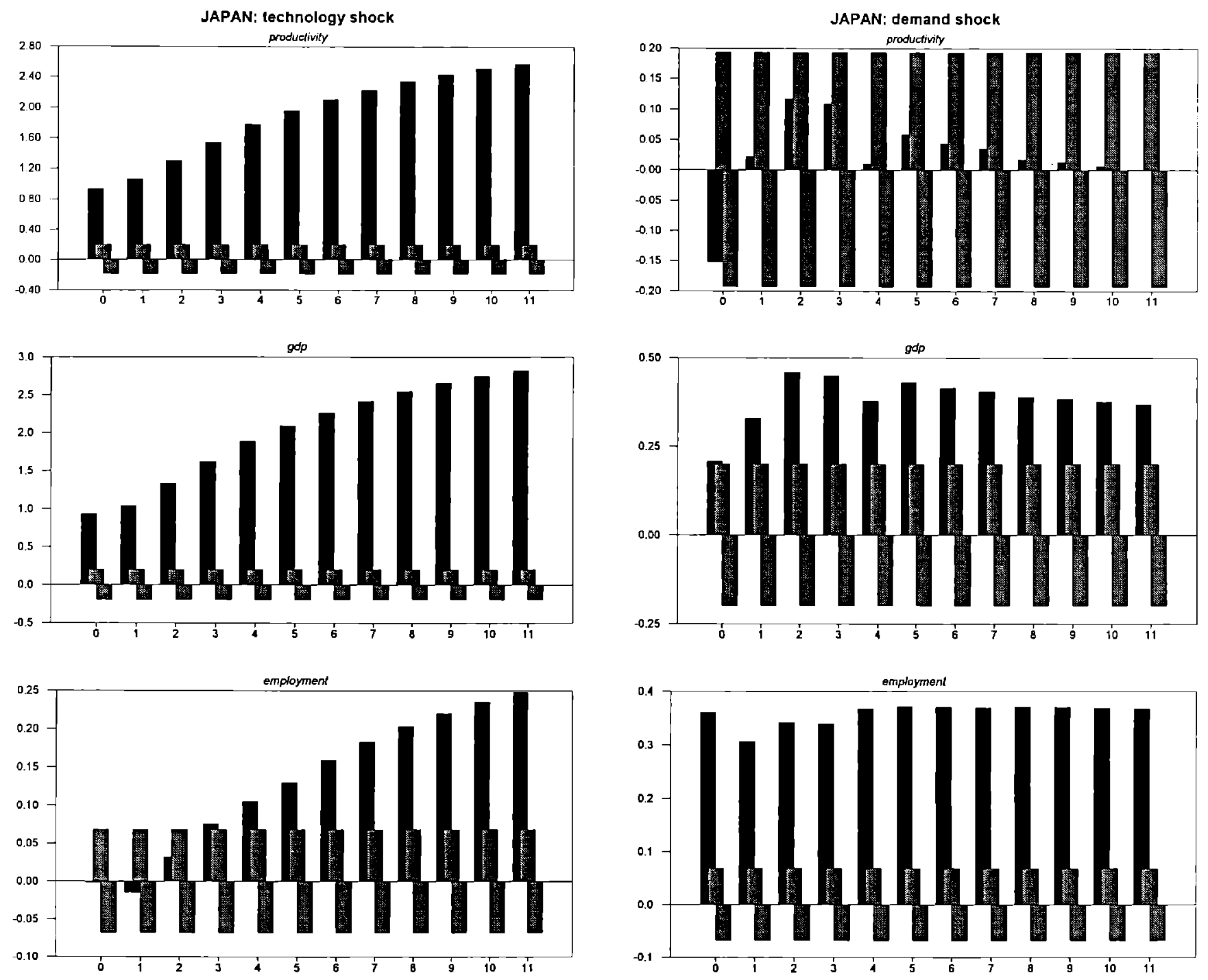

Figure 5.f. 
Decomposing the Business Cycle: Technology vs. Demand
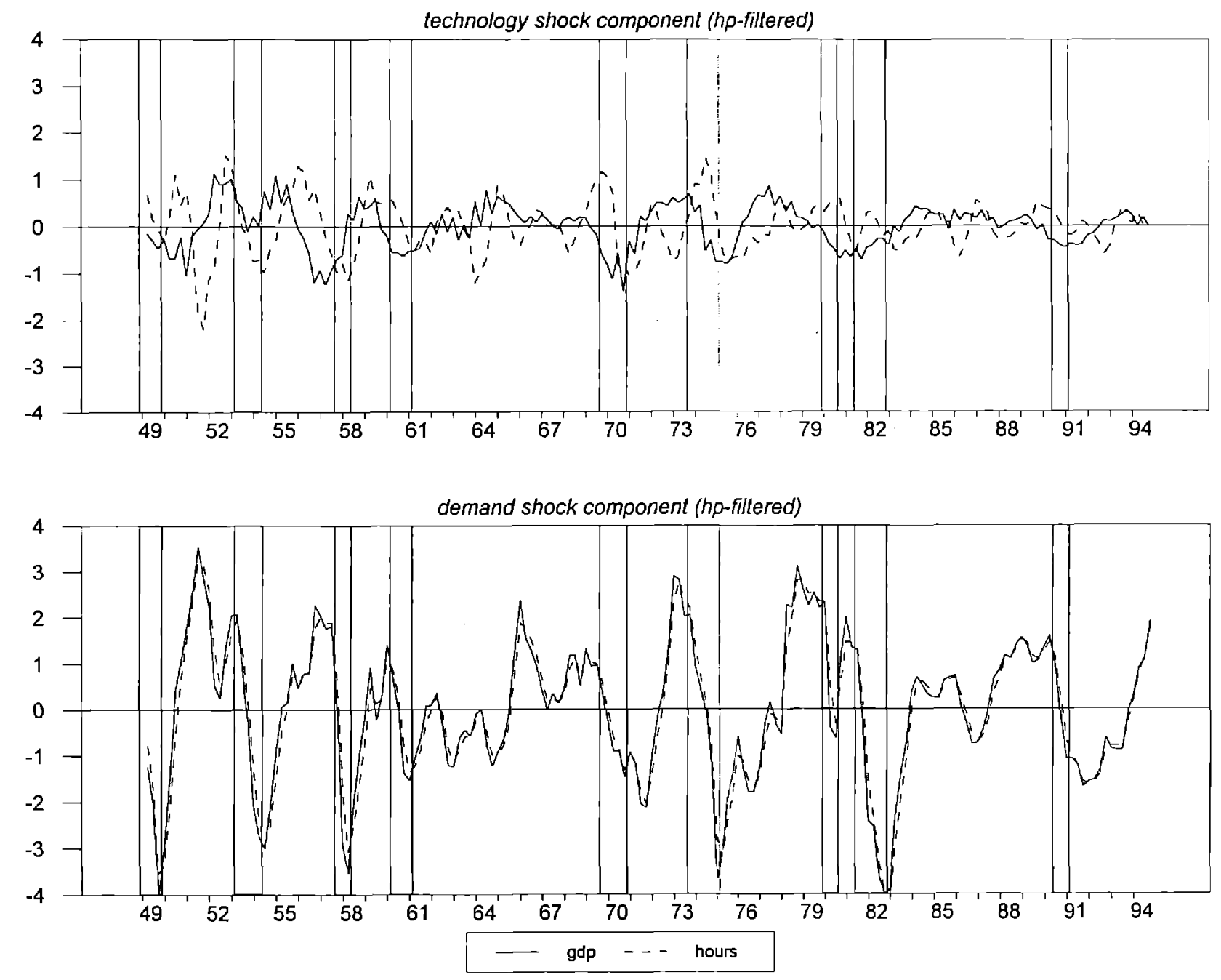